\title{
Tanshinol Attenuates the Deleterious Effects of Oxidative Stress on Osteoblastic Differentiation via Wnt/FoxO3a Signaling
}

\author{
Yajun Yang, ${ }^{1,2}$ Yanjie Su, ${ }^{2}$ Dongtao Wang, ${ }^{1}$ Yahui Chen, ${ }^{2}$ Tie Wu, ${ }^{2}$ Gang $\mathrm{Li}^{3}$ \\ Xuegang Sun, ${ }^{1}$ and Liao Cui ${ }^{1,2}$ \\ ${ }^{1}$ The Key Laboratory of Molecular Biology, State Administration of Traditional Chinese Medicine, \\ School of Traditional Chinese Medicine, Southern Medical University, Guangzhou 510515, China \\ ${ }^{2}$ Department of Pharmacology, Guangdong Key Laboratory for RङD of Natural Drug, Guangdong Medical College, \\ Zhanjiang 524023, China \\ ${ }^{3}$ Department of Orthopaedics and Traumatology, Faculty of Medicine, the Chinese University of Hong Kong, Hong Kong
}

Correspondence should be addressed to Xuegang Sun; sxg_smu@126.com and Liao Cui; cuiliao@163.com

Received 8 October 2013; Revised 3 December 2013; Accepted 4 December 2013

Academic Editor: Mohammad Abdollahi

Copyright () 2013 Yajun Yang et al. This is an open access article distributed under the Creative Commons Attribution License, which permits unrestricted use, distribution, and reproduction in any medium, provided the original work is properly cited.

There is now increasing evidence which suggests a pivotal role for oxidative stress in the development and progression of osteoporosis. We confirm herein the protective effects of natural antioxidant Tanshinol against oxidative stress in osteoblastic differentiation and the underlying mechanism. Our results show that hydrogen peroxide $\left(\mathrm{H}_{2} \mathrm{O}_{2}\right)$ leads to accumulation of reactive oxygen species (ROS), decrease in cell viability, cell cycle arrest and apoptosis in a caspase-3-dependent manner, and inhibition of osteoblastic differentiation. Tanshinol reverses these deleterious consequence triggered by oxidative stress. Moreover, under the condition of oxidative stress, Tanshinol suppresses the activation of FoxO3a transcription factor and expressions of its target genes Gadd45a and catalase (CAT) and simultaneously counteracts the inhibition of Wnt signalling and expressions of target genes Axin2, alkaline phosphatase $(A L P)$, and Osteoprotegerin $(O P G)$. The findings are further consolidated using FoxO3a siRNA interference and overexpression of Tcf4. The results illustrate that Tanshinol attenuates oxidative stress via down-regulation of FoxO3a signaling, and rescues the decrease of osteoblastic differentiation through upregulation of Wnt signal under oxidative stress. The present findings suggest that the beneficial effects of Tanshinol may be adopted as a novel therapeutic approach in recently recognized conditions of niche targeting osteoporosis.

\section{Introduction}

Extensive evidence indicates that "oxidative stress" theory has currently been proposed as a new intensive mechanism that the development and progression of osteoporosis are in connection with an increase of oxidative stress, which leads to degenerative disease of bone tissue $[1,2]$. Understanding of oxidative stress is currently a substantial topic of investigation with the aim of developing new ways to diminish negative effects of oxidative damage on bone metabolism [3]. Starting in their mid-40s, both genders experience a progressive decrease in bone mass and bone quality [2], associated with aging [4], some illnesses, or use of medications, such as diabetes or excessive exposure to glucocorticoids [5-7]. Notwithstanding, as for the evidence for physiological levels of reactive oxygen species (ROS) helpful in sustaining cellular function [8], it is generally believed that excessive accumulation of ROS causes oxidative stress and destroys proteins, lipids, and DNA, consequentially leading to cell death [9]. Based on current understanding of the cellular events of bone formation phase in the process of bone remodeling, increasing numbers of investigators have unraveled the potential mechanisms by which oxidative stress elicits a series of deleterious events in osteoblasts and ultimately contributes to osteoporosis [10, 11]. A sufficient number of mature osteoblastic cells are mainly required by bone formation during an episode of bone remodeling. The vast majority of Mesenchymal or stromal stem cells, 
however, fail to differentiate into osteoblast lineage cells by virtue of undergoing apoptosis under the condition of oxidative stress, which is responsible for the impairment of bone formation $[12,13]$. Meanwhile, oxidative stress can also cause the increase in osteoclasts activity and upregulation of osteoclast differentiation $[14,15]$. Therefore, a widely accepted participant in the pathogenesis of osteoporosis is oxidative stress, which causes a progressive increase in the prevalence of osteoblasts apoptosis, as well as an overwhelming decrease in the number of osteoblasts and bone formation rate. To sum up, impaired balance of bone remodeling may substantially contribute to bone loss under oxidative stress.

Cells neutralize the deleterious effects of ROS by upregulating enzymatic scavengers like Catalase (CAT), and simultaneously by inducing DNA-damage repair genes such as Gadd45a, as well as several proapoptotic genes for the elimination of damaged or abnormal cells [3]. The response involves a series of molecular events initiated by activation of Forkhead box O (FoxO) transcription factors, which acts as an important defense mechanism against oxidative stress [11]. Mammalian FoxOs consist of four molecules, including FoxO1, FoxO3a, FoxO4, and FoxO6, which participate in the modulation of cellular proliferation, differentiation, and longevity in a variety of cells [3]. Several types of remoldingrelated cells in the bone tissue express FoxO1-3, of which FoxO3 is the predominant one, whereas FoxO6 is restricted to the developing brain $[16,17]$. Activation of FoxO3a transcription factor by ROS antagonizes Wnt signaling, an essential stimulus for osteoblastogenesis [11]. Importantly, $\beta$ catenin is not only a fundamental coactivator of FoxO3a for resistance to oxidative stress, but also a requisite mediator for downstream effector Tcf of canonical Wnt pathway, contributing to the regulation of bone mass $[11,18]$.

Antioxidants, generally used as healthy food or medicinal agents, have been suggested to have beneficial effects in oxidative stress-associated diseases. Recently, it was reported that endogenous antioxidant levels decreased to a low degree in osteoporosis patients, and vitamin $\mathrm{C}$ intake showed significant advantages in raising bone mineral density (BMD) [19]. To date, administration of antioxidant was ascertained to exhibit an inhibitory effect on ovariectomy-induced bone loss in rodent osteoporosis model [20]. Previous findings have demonstrated that $D(+) \beta-3,4$-dihydroxyphenyl lactic acid (Tanshinol, or named Danshensu) isolated from Salvia miltiorrhiza Bunge exerted the inhibitory influence on oxidative stress using in vivo and in vitro model systems [21-24]. The previous studies in our group indicated that Tanshinol protected bone from long-term use of excessive prednisoneinduced bone marrow impairment by stimulating osteogenesis and depressing adipogenesis in bone marrow stromal cells (MSC) [25]. Furthermore, Tanshinol helps increase the expressions of Runx 2 and $\beta$-catenin mRNA and decrease Dickkopf 1 (Dkk1) and Peroxisome Proliferator-activated receptor $(\operatorname{PPAR} \gamma) \mathrm{mRNA}$, which contributes to the positive impact on osteoblastic differentiation in rat MSC [26]. In addition, Resveratrol is a well-known antioxidant containing polyphenolic acid structure similar to Tanshinol (Figure 2(c)) and has been used as one of investigative tools for phytoestrogen to deal with osteoporosis [27-30]. The previous findings show that Resveratrol exerts protective effect on counteracting oxidative stress via the regulation of FoxO3a pathway $[31,32]$. Hence, Tanshinol may abrogate the activation of FoxO3a signaling in response to oxidative stress, rescuing the dysregulation of Wnt signaling. However, evidence from the influence of Tanshinol on osteoblastic differentiation under oxidative stress and the underlying mechanisms remain to be elucidated. Additionally, Tanshinol, as principal active ingredient in many traditional Chinese medicine, has been widely used clinically for the treatment of cardiovascular diseases [33]. As a result, Tanshinol with advantages of clinical use may be developed as a potential candidate for prevention and/or treatment of osteoporosis.

Based on the arguments above, the aim of this study is to test the hypothesis that Tanshinol attenuates the deleterious effects of oxidative stress on osteoblastic differentiation in pluripotent mesenchymal precursor $\mathrm{C} 2 \mathrm{C} 12$ cells and that the underlying mechanism may be involved in antagonizing the suppressing effects of oxidative stress via promoting the activation of canonical Wnt signaling and simultaneously abrogating the activation of FoxO3a pathway in $\mathrm{C} 2 \mathrm{C} 12$ cells and preosteoblastic MC3T3-E1cells.

\section{Materials and Methods}

2.1. Chemicals, Reagents, and Plasmids. Wnt3a and Dkk1 recombinant proteins were purchased from R\&D Systems (Minneapolis, MN, USA). Recombinant human bone morphogenetic protein (BMP-2) was obtained from Peprotech (Rockyville, NJ, USA). Cignal FoxO3a reporter (FoxO3a-luc) and Cignal Tcf reporter (Tcf-luc) were purchased from Qiagen (Frederick, MD, USA). pcDNA3- $\beta$-catenin, pcDNA3Tcf4, and pcDNA3 plasmid (empty vector) control were obtained from Guangzhou Promoter (Guangzhou, Guangdong, China). FoxO3a siRNA and the scrambled siRNA (scrambled) control were supplied by Shanghai GenePharma (Shanghai, China). Dual-luciferase reporter assay kit was purchased from Promega (Madison, WI, USA). ALP staining kit and Nuclear Protein Extraction Kit were obtained from Beyotime (Haimen, Jiangsu, China). Active caspase-3 ELISA kit and osteocalcin ELISA kit were purchased from Tuo Ke Da (Guangzhou, Guangdong, China). LY294002, $\beta$-catenin, FoxO3a, and $\beta$-actin antibodies were purchased from Cell Signaling Technologies (Boston, MA, USA). Histone $\mathrm{H} 3$ antibody was obtained from Santa cruz (Paso Robles, CA, USA). Hoechst 33258 and $\mathrm{LiCl}$ were purchased from Amresco (Solon, OH, USA). $\mathrm{H}_{2} \mathrm{O}_{2}$, MTT, Propidium iodide (PI), alizarin red S, and $2^{\prime}, 7^{\prime}$-dichlorodihydrofluorescein diacetate (DCFH-DA) were purchased from Sigma-Aldrich (St. Louis, MO, USA). Tanshinol and Resveratrol (positive control, abbreviated as Res.) were purchased from PI\&PI (Guangzhou, Guangdong, China).

2.2. Cell Culture, Transfection, and Luciferase Activity. The pluripotent mesenchymal precursor $\mathrm{C} 2 \mathrm{C} 12$ cells and preosteoblastic MC3T3-E1 cells were obtained from American Type Culture Collection (ATCC, Manassas, VA, USA) and cultured in Dulbecco's modified Eagle's medium (DMEM) 
and $\alpha$-modified Eagle's medium ( $\alpha$-DMEM), respectively. Media were supplemented with $10 \%$ fetal bovine serum (FBS) and $1 \%$ each of penicillin, streptomycin, and glutamine and $1 \%$ sodium pyruvate. Cells were cotransfected transiently with indicated luciferase reporter constructs together with siRNA or overexpression constructs. Negative control was used with either scrambled RNA or empty vector plasmid. Cells were plated in 96-well plates at a density of $2 \times$ $10^{4}$ cells $/ \mathrm{cm}^{2}$ and transfected with a total of $0.3 \mu \mathrm{g}$ RNA and/or $0.2 \mu \mathrm{g}$ of DNA for 16 hours. Transfected cells were refreshed with fresh media and cultured for additional 8 hours. Subsequently, cells were serum starved by culturing in the presence of $2 \%$ FBS for 4 hours and treated with or without Tanshinol for 1 hour, followed by vehicle control (Con), $\mathrm{H}_{2} \mathrm{O}_{2}$, and/or related reagents, at indicated concentrations for 24 hours. Luciferase activity was measured using the Dual-Luciferase Reporter Assay System according to the manufacturer's instructions.

2.3. Cell Viability Assay. Cells were plated in their growth media in 96-well plates. After 24 hours of plating, cells were treated with indicated reagents and cultured sequentially for the indicated time period. After incubation with different treatments above, cells were cultured for further 4 hours at $37^{\circ} \mathrm{C}$ in refreshed media containing MTT $(5 \mathrm{mg} / \mathrm{mL})$. Then, the formazan crystals were solubilized in dimethyl sulfoxide (DMSO) and absorbance was measured at a wavelength of $570 \mathrm{~nm}$ using a microplate reader (Thermo Fisher Scientific, Vantaa, Finland).

2.4. Phenotypic Characterization of Osteoblastic Differentiation. C2C12 cells were seeded at a density of $2.4 \times$ $10^{4}$ cells $/ \mathrm{cm}^{2}$. At confluence, cells were cultured in osteogenic medium containing 5\% FBS and BMP-2 (100 ng/mL) in the presence or absence of indicated reagents. The media were changed every 3-4 days. To identify committed osteoblasts, ALP staining was performed at day 3 using ALP Colour Development Kit. The stained cellular images were acquired by Eclipse E800 microscope (Nikon, Tokyo, Japan). For quantitative determination of ALP activity at day 3, cells were lysed in $100 \mathrm{mM}$ glycine, $1 \mathrm{mM} \mathrm{MgCl}$, and $1 \%$ Triton $\mathrm{X}-100$ at $\mathrm{pH}$ 10. Cell lysates were subjected to ALP activity using an ALP assay kit (Nanjing Jiancheng Biotech, China). Osteocalcin secretion in supernatants of the media at day 3 was measured using ELISA kit, as described in detail elsewhere [34]. Both ALP activity and osteocalcin concentration were normalized with total cellular protein contents, which were determined by a micro-Bradford assay. To measure mineralization activity, cells were stained with alizarin red $\mathrm{S}$, as previously described [35]. Red staining was visualized and the representative pictures were photographed with the microscope mentioned above.

2.5. Oxidative Stress Assay. The intracellular oxidative stress was probed by DCFH-DA and quantified using flow cytometry. Briefly, cells were harvested by trypsinization and labeled with DCFH-DA $(20 \mu \mathrm{M})$ for $30 \mathrm{~min}$ at $37^{\circ} \mathrm{C}$. Subsequently, cells were exposed to $\mathrm{H}_{2} \mathrm{O}_{2}$ in the presence or absence of
Tanshinol or Resveratrol for $30 \mathrm{~min}$, followed by fluorescence intensity acquirement using BD FACSCalibur flow cytometry (BD Biosciences, San Jose, CA, USA). Acquired data were analyzed with CellQuest Pro software (BD Biosciences, San Jose, CA, USA).

2.6. Cell Cycle Progression and Apoptosis Measurements. Cell cycle distributions were determined by flow cytometry to count cells stained with PI as described previously [36]. Morphological alteration of apoptotic cells was observed with Hoechst $33258(20 \mu \mathrm{M})$ [37], and fluorescent images were acquired by the microscopy mentioned above. Apoptotic cells characterized by nuclear damages and normal cells with round intact nuclear morphology were counted by Image J 1.46r software, respectively. Differences in ultrastructural morphology between normal cells and apoptotic cells were measured using transmission electron microscopy (TEM: H7650, Hitachi, Tokyo, Japan), as described previously [38]. For cleaved caspase-3 assay, cells were harvested and lysed as described above. The activity of cleaved caspase- 3 in cell lysates was determined using ELISA kit and normalized with total protein contents.

2.7. Quantitative RT-PCR Detection. RNA isolation and quantitative real-time polymerase chain reaction (qRT-PCR) were performed as described previously [39]. Briefly, total RNA from each indicated group was extracted by using TRIzol reagent. Complementary DNA (cDNA) was synthesized, and qRT-PCR was performed on a Stratagene Mx3005P QPCR System (La Jolla, CA, USA). The designed paired primers were as follows: Gadd45a, $5^{\prime}$-GGGCTCAGAGATGACTTTGC-3' (forward), $5^{\prime}$-TTTTTGTCCCTTTTGCCTTG-3' (reverse); CAT, $5^{\prime}$-CCTCGTTCAGGATGTGGTTT-3' (forward), $5^{\prime}$-TCTGGTGATATCGTGGGTGA-3' (reverse); Axin2, $5^{\prime}$-CTCCCCACCTTGAATGAAGA-3' (forward), $5^{\prime}$-ACTGGGTCGCTTCTCTTGAA-3' (reverse); ALP, $5^{\prime}$ AACCCAGACACAAGCATTCC-3' (forward), $5^{\prime}$-GCCTTTGAGGTTTTTGGTCA-3' (reverse); OPG, $5^{\prime}$-GCAGAAGGAACTGCAACACA-3' (forward), 5' -ATGGTGAGGTGTGCAAATG-3' (reverse); GAPDH, $5^{\prime}$-ATTGTCAGCAATGCATCCTG-3' (forward), 5'-ATGGACTGTGGtcATGAGCC-3' (reverse). PCR results were analyzed using Opticon Monitor Analysis 2.0 software (Bio-Rad Laboratories, Hercules, CA, USA). Relative mRNA expression was quantified by subtracting the glyceraldehyde 3-phosphate dehydrogenase $(\mathrm{GAPDH})$ threshold cycle $\left(C_{t}\right)$ value from the $C_{t}$ value of the genes of interest and expressed as $2^{-\Delta C_{t}}$, as described by the protocol of the manufacturer.

2.8. Western Blotting Analysis. For detection of $\beta$-catenin expression, cells were lysed by RIPA buffer. For measurement of FoxO3a protein, cells were homogenized for measurement of total FoxO3a and further extracted by nuclear extraction reagents for nuclear FoxO3a according to the instructions of the manufacturer, as described previously [40, 41]. The protein expression was monitored by the measurement of Chemiluminescence alterations using Image Station 2000 MM (Eastman Kodak, Rochester, NY, USA). 
2.9. Statistical Analysis. ANOVA (SPSS 13.0) was used to detect effects of various treatments after establishing that the data were normally distributed and equivalency of variances. Samples were considered normally distributed if $P>0.05$. Homogeneity of variance of the samples to be compared was tested by using a Levene's test. Heterogeneity of variance was accepted if $P>0.05$, and LSD method was used to perform appropriate pairwise comparisons of treatment groups. Otherwise, Dunn's method for post hoc test was used to perform pairwise comparisons of treatment groups. Unless otherwise stated, results are presented as mean \pm SEM and performed in triplicate and repeated at least one time.

\section{Results}

3.1. Tanshinol Ameliorates the Decrease of Cell Viability Induced by $\mathrm{H}_{2} \mathrm{O}_{2}$. To test the effects of Tanshinol on cell growth, either C2C12 cells or MC3T3-E1 cells were exposed to Tanshinol in the tenfold increasing concentrations varied from 0.0001 to $1000 \mu \mathrm{M}$ for a period of $24 \mathrm{~h}$. The results showed that Tanshinol with the experimental concentrations exerted no inhibitory effects on the growth of the two cells and that an increase in viability was observed in the two cell lines treated with Tanshinol, especially at the concentration of $1 \mu \mathrm{M}$ (Figures $1(\mathrm{a})$ and $1(\mathrm{~b})$ ).

Cellular responses induced by $\mathrm{H}_{2} \mathrm{O}_{2}$ depend upon the severity of the cell damages, which are further influenced by magnitude of the dose. Therefore, we examined the viability of $\mathrm{C} 2 \mathrm{C} 12$ cells treated with increasing concentrations of $\mathrm{H}_{2} \mathrm{O}_{2}$ ranging from $0.025 \mathrm{mM}$ to $1.2 \mathrm{mM}$ for a period of $24 \mathrm{~h}$. As shown in Figure 2(a), cell viability showed a distinct trend toward reduction in a concentration-dependent manner in C2C12 cells treated with indicated concentration of $\mathrm{H}_{2} \mathrm{O}_{2}$ for $24 \mathrm{~h}$, and there was a significant difference in high dose ( $0.2 \mathrm{mM}$ or above) of $\mathrm{H}_{2} \mathrm{O}_{2}$. In contrast, cell viability showed no statistical alterations in $\mathrm{C} 2 \mathrm{C} 12$ cells treated with $\mathrm{H}_{2} \mathrm{O}_{2}$ at low doses ( $0.1 \mathrm{mM}$ or below). Next, the influence of Tanshinol $(1 \mu \mathrm{M})$ in preventing $\mathrm{H}_{2} \mathrm{O}_{2}(0.2 \mathrm{mM})$-induced cell death was determined at different time points from $0 \mathrm{~h}, 12 \mathrm{~h}, 24 \mathrm{~h}$, $36 \mathrm{~h}$, to $48 \mathrm{~h}$. It was obvious that 24 -h treatment with $1 \mu \mathrm{M}$ Tanshinol could block the decrease of cell viability induced by $\mathrm{H}_{2} \mathrm{O}_{2}$ (Figure 2(b)). Based on these results, $\mathrm{H}_{2} \mathrm{O}_{2}$ at the dose of $0.2 \mathrm{mM}$ and Tanshinol at the concentration of $1 \mu \mathrm{M}$ were adopted in the subsequent experiments.

3.2. Tanshinol Attenuates Oxidative Stress Triggered by $\mathrm{H}_{2} \mathrm{O}_{2}$. It is well known that intracellular ROS generation in response to oxidants stimuli contributes to a series of concomitant molecule events for oxidative stress. DCFH-DA is widely used as indicative of intracellular ROS generation [42]. To further examine whether Tanshinol with polyphenolic hydroxyl groups (Figure 2(c)) exerted an influence on suppression of cell death implicated in counteracting $\mathrm{H}_{2} \mathrm{O}_{2}$ induced oxidative stress, we measured intracellular ROS of C2C12 cells exposed to $\mathrm{H}_{2} \mathrm{O}_{2}(0.2 \mathrm{mM})$. Negligible fluorescence was observed in vehicle-treated $\mathrm{C} 2 \mathrm{C} 12$ cells, whereas a remarkable increase of arbitrary fluorescence unit was detected in cells treated with $\mathrm{H}_{2} \mathrm{O}_{2}$ for $30 \mathrm{~min}$, reaching

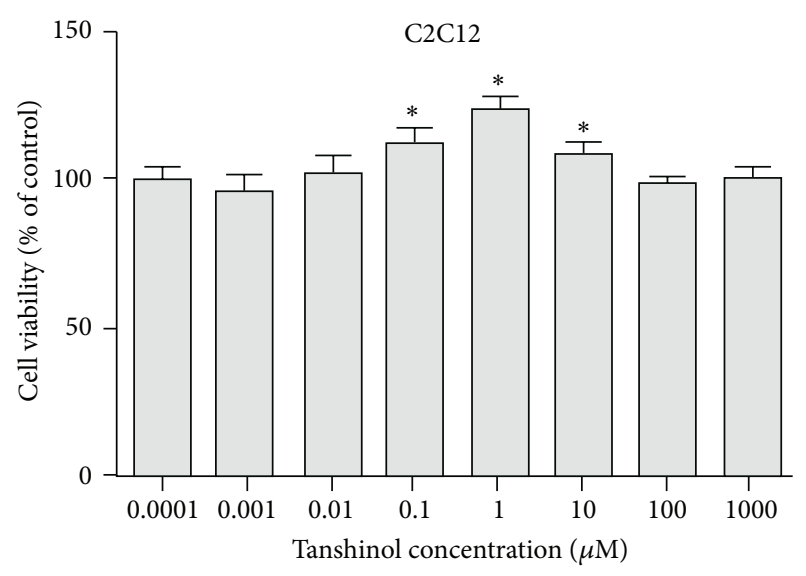

(a)

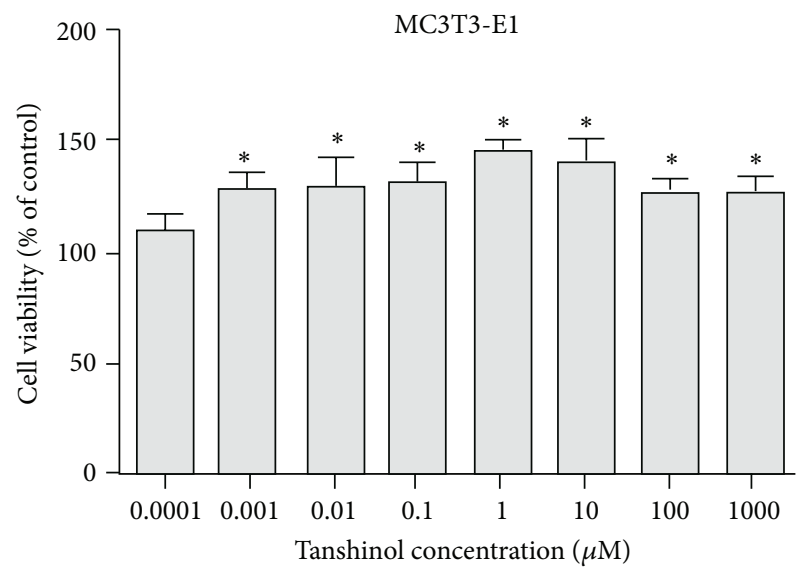

(b)

FIgURE 1: Effects of Tanshinol on cell viability of C2C12 cells and MC3T3-E1 cells. (a) Cell viability was measured by MTT assay in pluripotent mesenchymal precursor C2C12 cells and (b) preosteoblastic MC3T3-E1 cells treated with or without the indicated concentrations of Tanshinol for $24 \mathrm{~h}$. Data are given as mean \pm SEM of at least three independent experiments. ${ }^{*} P<0.05$ versus vehicle control.

an appropriately 7-fold higher than vehicle control. In contrast, treatment with either Tanshinol or resveratrol leads to the counteraction of ROS accumulation induced by $\mathrm{H}_{2} \mathrm{O}_{2}$ (Figure 2(d)). Additionally, the antioxidant effects of Tanshinol were indistinguishable from those of Resveratrol. Taken together, the results suggest that Tanshinol protects $\mathrm{C} 2 \mathrm{C} 12$ cells against $\mathrm{H}_{2} \mathrm{O}_{2}$-induced oxidative stress by scavenging ROS generation.

\subsection{Tanshinol Abrogates Inhibitory Effect of Oxidative Stress on} Osteoblastic Differentiation. Considering that BMP-2 treatment diverts $\mathrm{C} 2 \mathrm{C} 12$ cells from myogenic differentiation to the osteoblast lineage, we ascertained the optimal dose of BMP-2 $(100 \mathrm{ng} / \mathrm{mL})$ treatment with which the climax of ALP (a biomarker of osteoblastogenesis) mRNA expression was induced for $24 \mathrm{~h}$ (Figure 3(a)). To evaluate the capacity of Tanshinol or Resveratrol to protect $\mathrm{C} 2 \mathrm{C} 12$ cells against oxidative stress in the process of osteoblastic differentiation, 

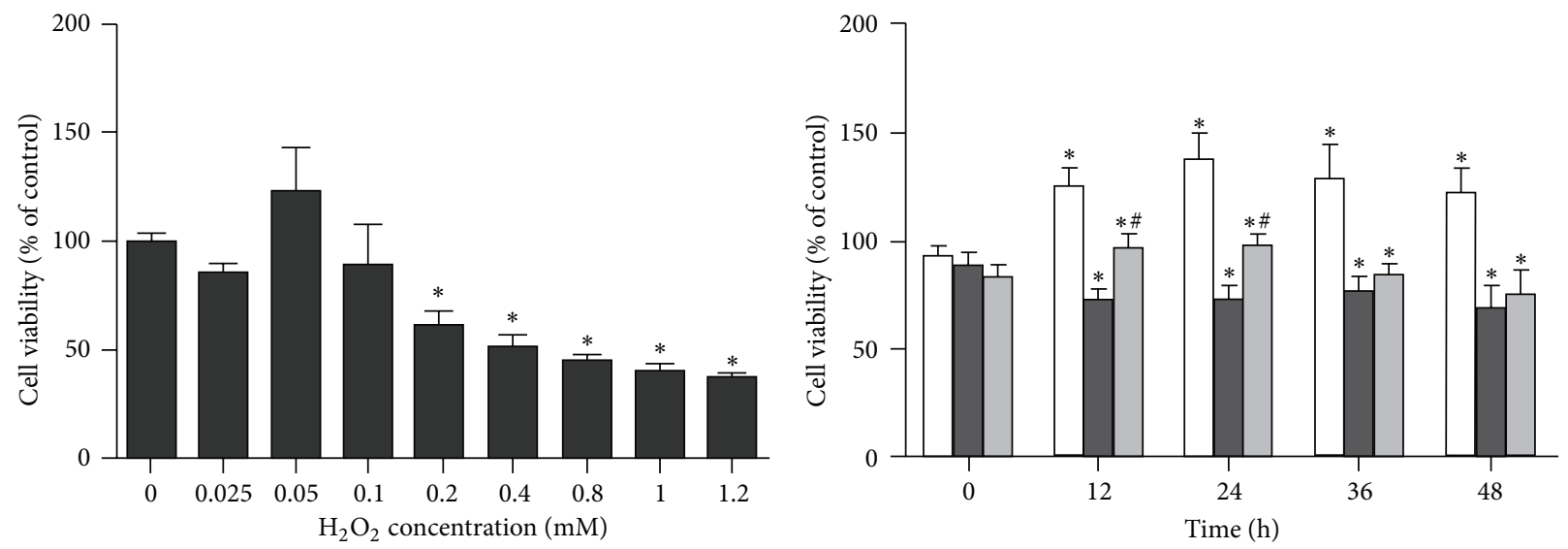

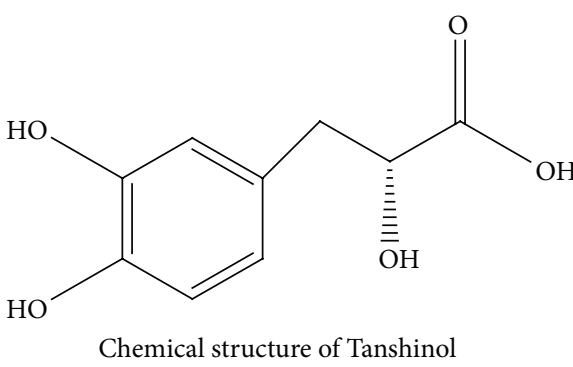

(c)

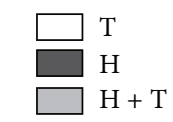

(a)

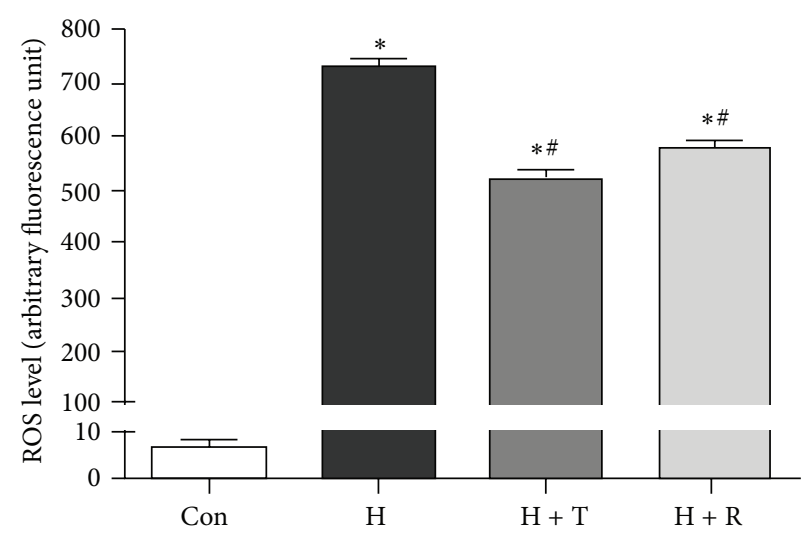

(d)

FIGURE 2: Protective effects of Tanshinol against $\mathrm{H}_{2} \mathrm{O}_{2}$-induced cell death and ROS generation. (a) Cell viability was measured by MTT assay in $\mathrm{C} 2 \mathrm{C} 12$ cells exposed to $\mathrm{H}_{2} \mathrm{O}_{2}$ at the indicated concentration for $24 \mathrm{~h}$. (b) $\mathrm{C} 2 \mathrm{C} 12$ cells were pretreated in the presence or absence of Tanshinol $(1 \mu \mathrm{M})$ for $1 \mathrm{~h}$ before the addition of $\mathrm{H}_{2} \mathrm{O}_{2}(200 \mu \mathrm{M})$ and were subsequently cultured for $0 \mathrm{~h}, 12 \mathrm{~h}, 24 \mathrm{~h}, 36 \mathrm{~h}$, and $48 \mathrm{~h}$, respectively. (c) The chemical structure of Tanshinol consists of polyphenolic hydroxyl groups. (d) C2C12 cells were pretreated as described in (b), followed by $\mathrm{H}_{2} \mathrm{O}_{2}(200 \mu \mathrm{M})$ for $24 \mathrm{~h}$, and the oxidative status of C2C12 cells was quantified by DCHF-DA to monitor the emitted fluorescence intensity resulting from intracellular oxidation using flow cytometry. Note: (1) Con (vehicle control); (2) $\mathrm{H}_{(}\left(\mathrm{H}_{2} \mathrm{O}_{2}\right) ;(3) \mathrm{H}+\mathrm{T}\left(\mathrm{H}_{2} \mathrm{O}_{2}+\right.$ Tanshinol); (4) $\mathrm{H}+\mathrm{R}\left(\mathrm{H}_{2} \mathrm{O}_{2}+\right.$ Resveratrol). Data are given as mean \pm SEM of at least three independent experiments. ${ }^{*} P<0.05$ versus vehicle control and ${ }^{\#} P<0.05$ versus $\mathrm{H}_{2} \mathrm{O}_{2}$ treatment.

we performed short-term osteoblast differentiation experiments. ALP staining and its intensity quantification indicated that, in comparison to vehicle control, both Tanshinol and Resveratrol display a significantly inhibitory influence on the decrease of cell populations stained positive for ALP under oxidative stress (Figures 3(b) and 3(c)). We next verified that Tanshinol could rescue the secreted osteocalcin in the supernatant of media and ALP level in the cell lysates in $\mathrm{C} 2 \mathrm{C} 12$ cells simulated by BMP-2 at day 3 under oxidative stress, as well as Resveratrol (Figures 3(d) and 3(e)). Additionally, C2C12 cells committed to osteoblast were investigated by alizarin red $S$ staining after long-term cultures to depict mineralization of the osteoblast nodules. The extent of alizarin red $\mathrm{S}$ staining decreased significantly in $\mathrm{C} 2 \mathrm{C} 12$ cells exposed to $\mathrm{H}_{2} \mathrm{O}_{2}$ at day 10 , and either Tanshinol or
Resveratrol reversed the antagonistic effect of $\mathrm{H}_{2} \mathrm{O}_{2}$ on the osteogenic capacity (Figure 3(f)). Taken together, these lines of evidence in our experiments indicate that Tanshinol may counteract the deleterious effect of $\mathrm{H}_{2} \mathrm{O}_{2}$-elicited oxidative stress on BMP-2 inducible osteoblastic differentiation.

\subsection{Tanshinol Protects against $\mathrm{H}_{2} \mathrm{O}_{2}$-Induced Cell Cycle} Arrest and Apoptosis. Encouraged by the findings above, we proceeded to examine whether the decreased capacity of proliferation and differentiation elicited by oxidative stress is relevant to cell cycle arrest and apoptosis. To begin with, a sharp increase of the cell proportion in G0 phase was observed in $\mathrm{C} 2 \mathrm{C} 12$ cells exposed to $\mathrm{H}_{2} \mathrm{O}_{2}$, as well as a corresponding decrease of cells population in the both $\mathrm{S}$ phase and G2/M phase. Encouragingly, Tanshinol showed 


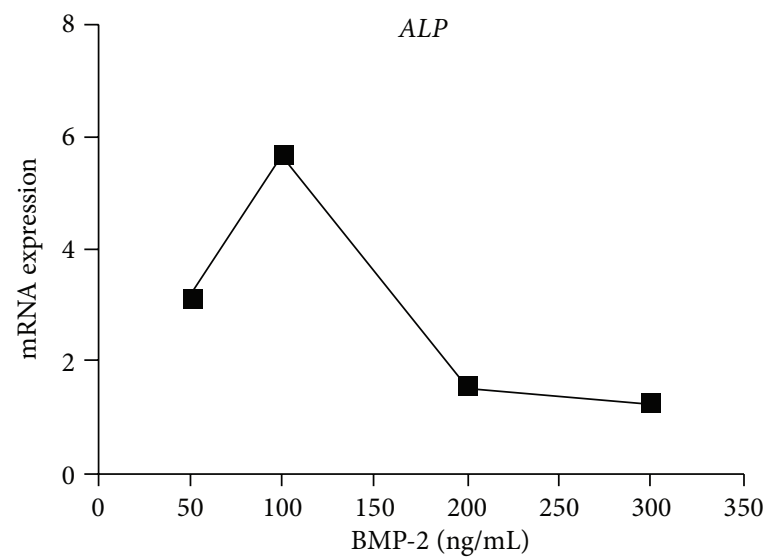

(a)
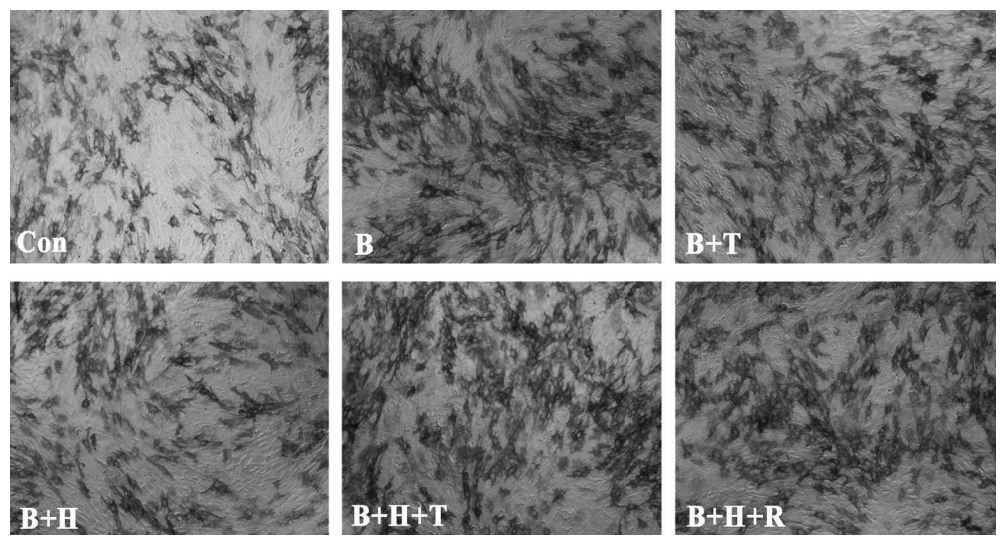

(b)

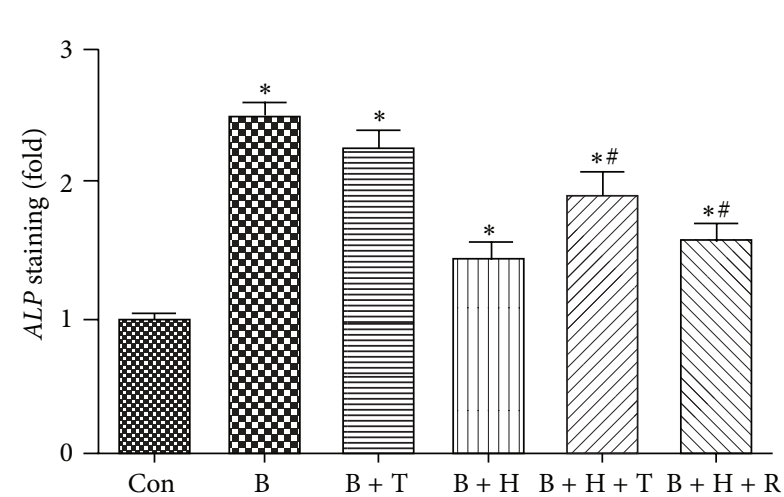

(c)

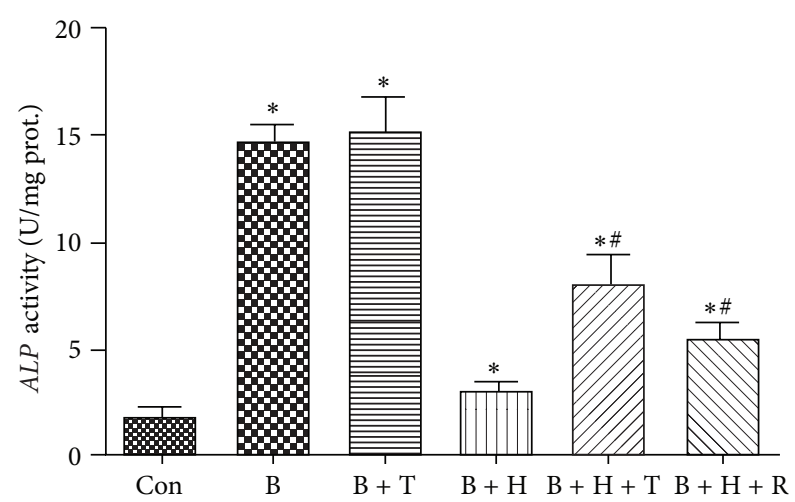

(d)

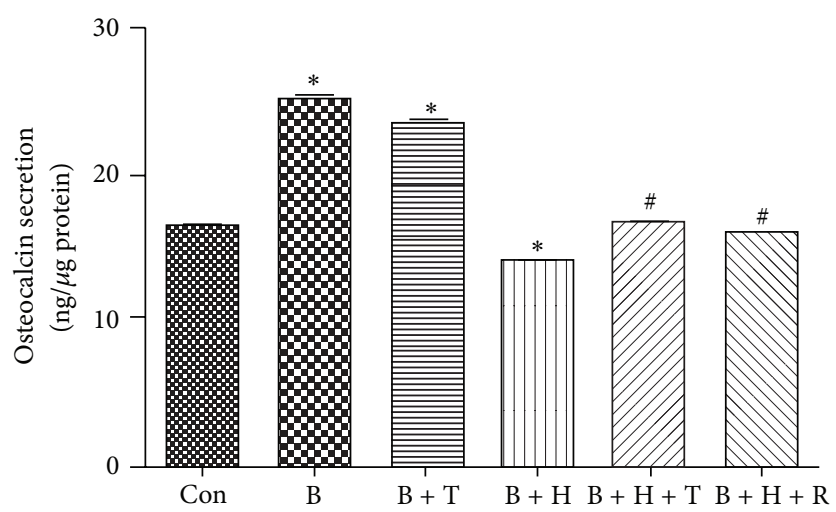

(e)

FIGURE 3: Continued. 

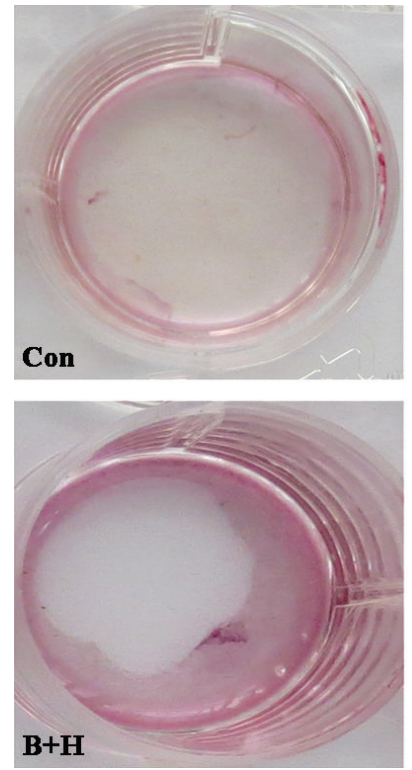
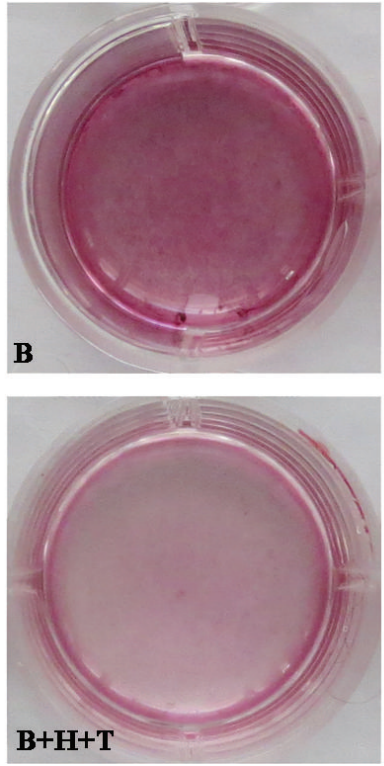
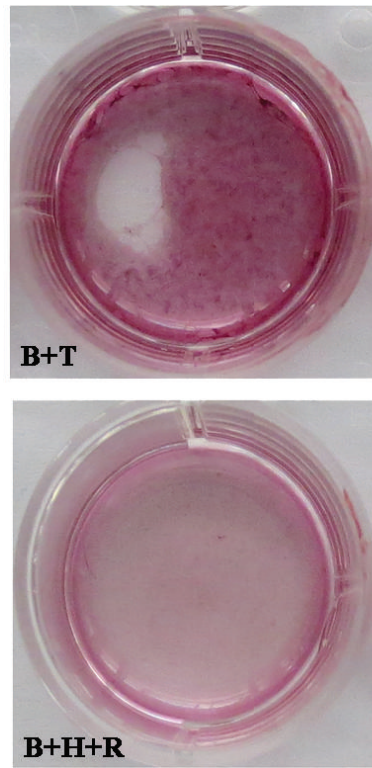

(f)

FIGURE 3: Tanshinol counteracts inhibitory effect of oxidative stress on osteoblastic differentiation. (a) C2C12 cells were treated with increasing concentrations of BMP-2 for $24 \mathrm{~h}$ to determine the optimal concentration using qRT-PCR. Cells were cotreated with BMP-2 (100 ng/mL) and Tanshinol $(1 \mu \mathrm{M})$ or Resveratrol $(1 \mu \mathrm{M})$ in the presence or absence of $\mathrm{H}_{2} \mathrm{O}_{2}(200 \mu \mathrm{M})$, and determinations were made as follows. (b) Cells were stained using ALP staining Kit, and (c) the percentage of positively stained cell populations was counted by Image J software to analyse the extent of osteoblastic differentiation at day 3; (d) ALP activity in the cell lysates and (e) osteocalcin secretion in the supernatant of media were measured by ALP Assay Kit and ELISA Kit at day 3, respectively; (f) mineralization activity with the indicated treatments was stained using alizarin red S at day 10. Note: (1) Con (vehicle control); (2) B (BMP-2); (3) B + T (BMP-2 + Tanshinol); (4) B + $\mathrm{H}\left(\mathrm{BMP}-2+\mathrm{H}_{2} \mathrm{O}_{2}\right) ;(5)$ $\mathrm{B}+\mathrm{H}+\mathrm{T}\left(\mathrm{BMP}-2+\mathrm{H}_{2} \mathrm{O}_{2}+\right.$ Tanshinol); (6) B $+\mathrm{H}+\mathrm{R}$ (BMP-2 $+\mathrm{H}_{2} \mathrm{O}_{2}+$ Resveratrol). Data shown are the mean \pm SEM of at least three independent experiments. ${ }^{*} P<0.05$ versus vehicle control and ${ }^{\#} P<0.05$ versus BMP- $2+\mathrm{H}_{2} \mathrm{O}_{2}$ treatment. Original magnification $\times 100$ in (b).

a capacity to reverse the cell cycle arrest at $\mathrm{S}$ and $\mathrm{G} 2 / \mathrm{M}$ phases, as effectively as Resveratrol, whereas $\mathrm{C} 2 \mathrm{C} 12$ cells treated with either Tanshinol or Resveratrol alone had no apparent influence on cell cycle progression (Figure 4(a)).

We next evaluated the changes of apoptosis morphology in the chromatin structure of C2C12 cells using Hoechst 33258 staining. The results showed that $\mathrm{C} 2 \mathrm{C} 12$ cells underwent apoptosis characterized by chromatin condensation, apoptotic bodies, and nuclear enlarged or fragments after treatments with $\mathrm{H}_{2} \mathrm{O}_{2}$ for $12 \mathrm{~h}$ (Figure $4(\mathrm{c})$ ). These morphological criteria of apoptotic alterations were further confirmed by ultrastructure analysis using TEM assay. A clearly apoptotic alteration occurred in $\mathrm{C} 2 \mathrm{C} 12$ cells stimulated by oxidative stress with characteristics of nuclear protrusion and swelling, cytoplasmic vacuoles, chromatin margination, and membrane disintegration (Figure 4(d)). Meanwhile, pretreatment for $12 \mathrm{~h}$ with Tanshinol or Resveratrol reduced the extent of apoptosis in $\mathrm{C} 2 \mathrm{C} 12$ cells exposed to $\mathrm{H}_{2} \mathrm{O}_{2}$ (Figures 4(c) and 4(d)). Caspase-3 is required for some typical hallmarks of apoptosis and is indispensable for cell death in a caspase-3-dependent manner that active Caspase3 executes eventually cell death program [2]. Therefore, we further ascertained that the activity of caspase- 3 cleavage in $\mathrm{H}_{2} \mathrm{O}_{2}$-treated cells was higher than that in cells exposed to vehicle control, and Tanshinol could suppress the deleterious influence (Figure 4(b)). Collectively, all these lines of evidence provide further support that Tanshinol is capable of abrogating apoptosis of $\mathrm{C} 2 \mathrm{C} 12$ cells triggered by oxidative stress.

3.5. Tanshinol Reverses Inhibition of Wnt/ $\beta$-Catenin Signaling Pathway under Conditions of Oxidative Stress. Based on the evidence mentioned above, we next asked whether Tanshinol promoted activation of Wnt signaling pathway required for osteoblast commitment under conditions of oxidative stress. Using Western Blot, we consolidated that the decrease of $\beta$ catenin (a key molecular of canonical Wnt signal transduction) in $\mathrm{C} 2 \mathrm{C} 12$ cells exposed to $\mathrm{H}_{2} \mathrm{O}_{2}$ was restored by the treatment of Tanshinol, just like Resveratrol (Figure 5(a)).

To elucidate the role of Tanshinol in upregulation of Wnt pathway under the condition of oxidative stress, we chose a direct measure to monitor Wnt signaling through alterations of Tcf-mediated transcription using a Tcf-luc reporter plasmid. As expected, the luciferase relative luminescence units (RLU) of Tcf-luc in $\mathrm{C} 2 \mathrm{C} 12$ cells treated with $\mathrm{H}_{2} \mathrm{O}_{2}$ were significantly declined to the extent of approximate half of the RLU in cells treated with vehicle control, and Tanshinol attenuated the decrease of RLU caused by oxidative stress. Moreover, Tanshinol treatment alone enhanced the increase of Tcf-luc activity, as effectively as treatment with Wnt3a, showing a more than 4-fold increase of RLU. Importantly, Tcf transcriptional activity stimulated by Tanshinol 

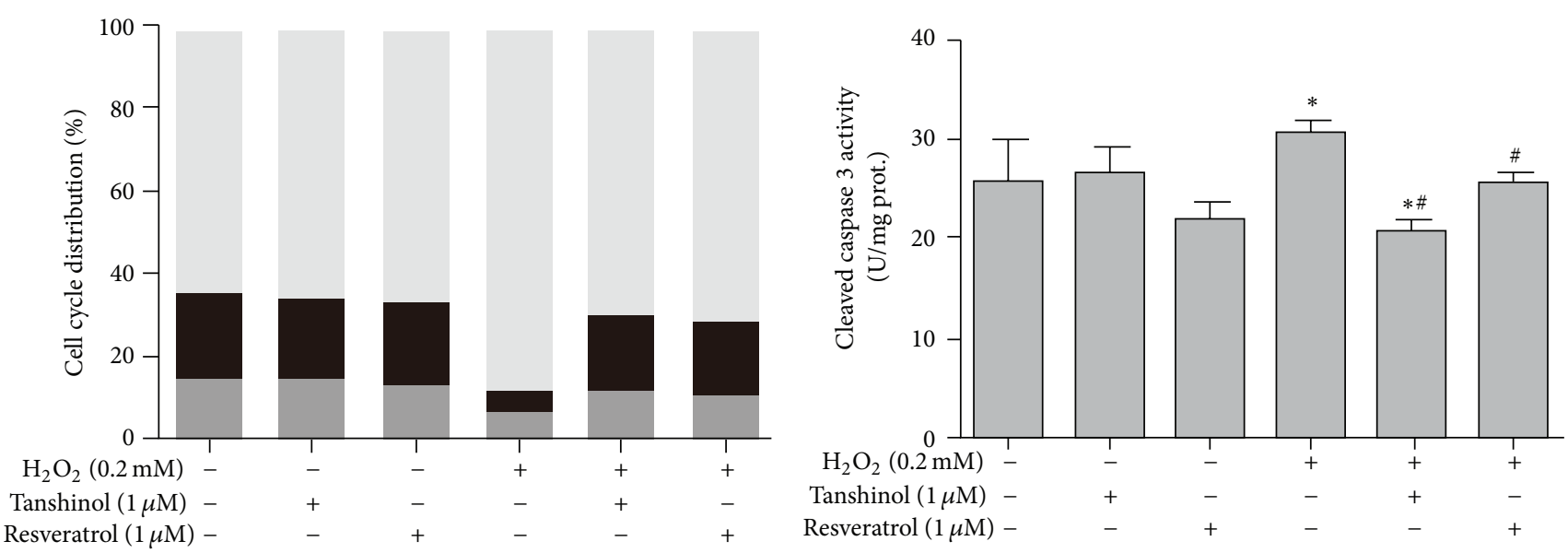

(a)

(b)
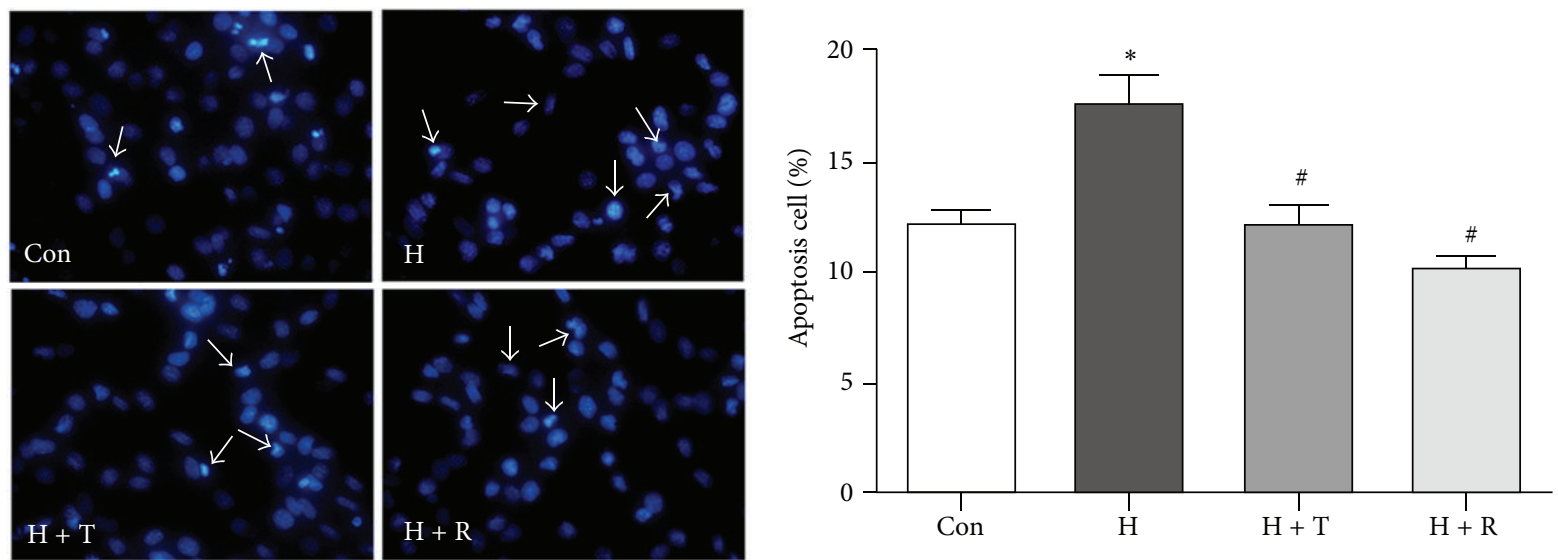

(c)
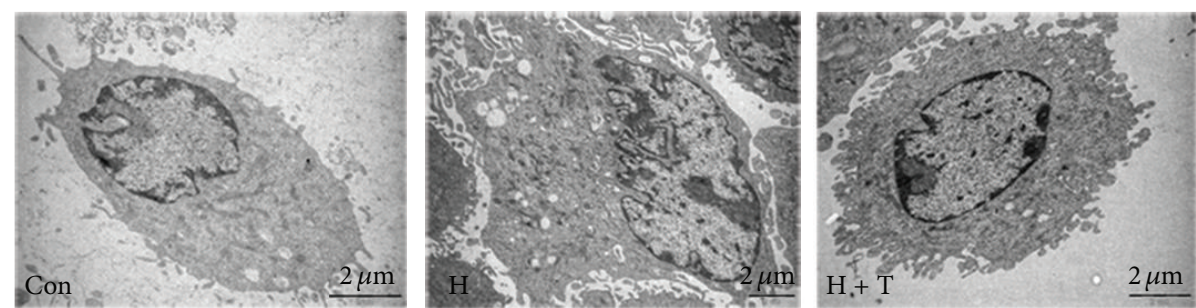

(d)

FIgURE 4: Tanshinol diminishes the cell cycle arrest and apoptosis under oxidative stress. C2C12 cells were pretreated with the indicated concentrations of Tanshinol or Resveratrol for $1 \mathrm{~h}$, followed by the treatment of vehicle control or $\mathrm{H}_{2} \mathrm{O}_{2}$ for $24 \mathrm{~h}$. The following measurements were carried out. (a) Analysis of cell cycle distribution was explored using flow cytometry; (b) the activation of caspase 3 was determined by ELISA kit; (c) observations of morphological alterations of apoptosis cells were addressed by Hoechst33258 staining (left panel) and counted by Image J software (right panel); (d) the ultrastructural differences between apoptosis cells and normal cells were examined using TEM. Note: (1) Con (vehicle control); (2) $\mathrm{H}\left(\mathrm{H}_{2} \mathrm{O}_{2}\right)$; (3) $\mathrm{H}+\mathrm{T}\left(\mathrm{H}_{2} \mathrm{O}_{2}+\right.$ Tanshinol); (4) $\mathrm{H}+\mathrm{R}\left(\mathrm{H}_{2} \mathrm{O}_{2}+\right.$ Resveratrol). Error bars indicate mean $\pm \mathrm{SEM}$ of at least three independent experiments. ${ }^{*} P<0.05$ versus vehicle control and ${ }^{*} P<0.05$ versus $\mathrm{H}_{2} \mathrm{O}_{2}$ treatment. Original magnification $\times 400$ in (c) (left panel). 

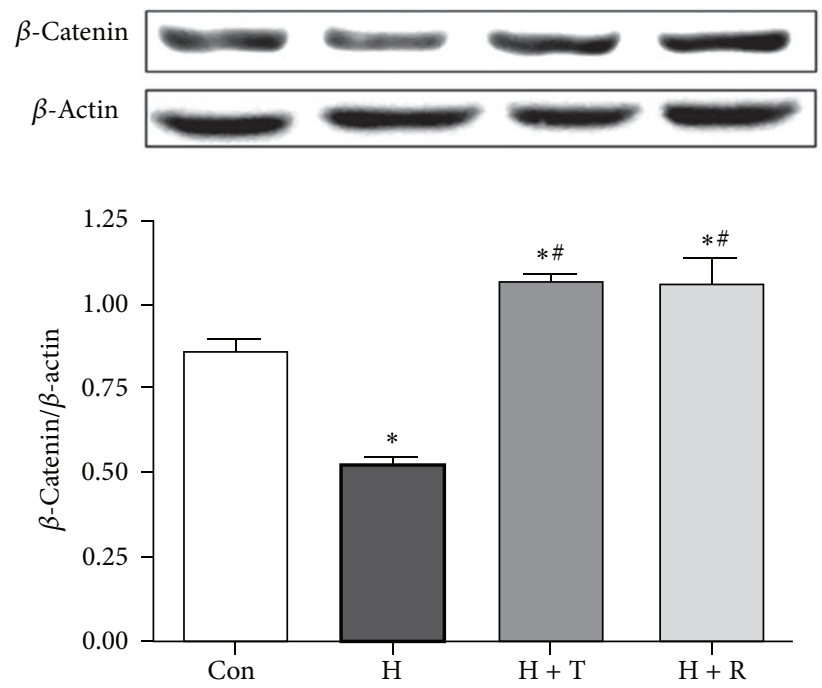

(a)
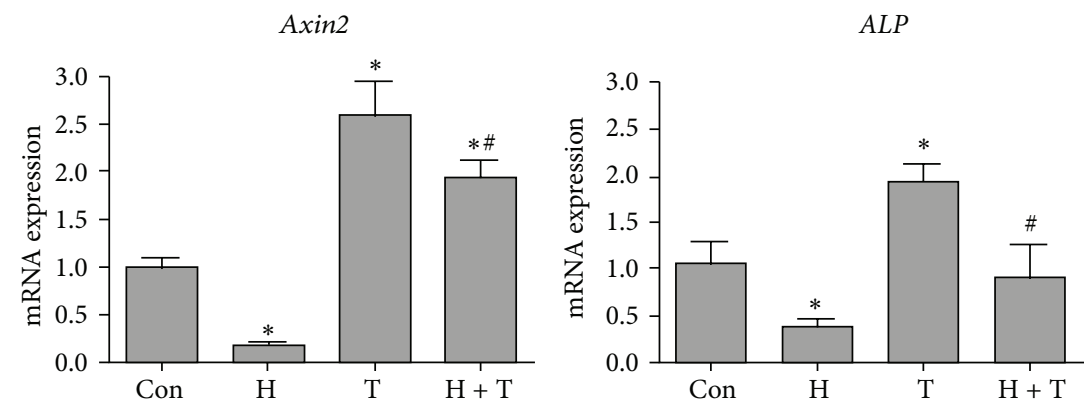

(c)

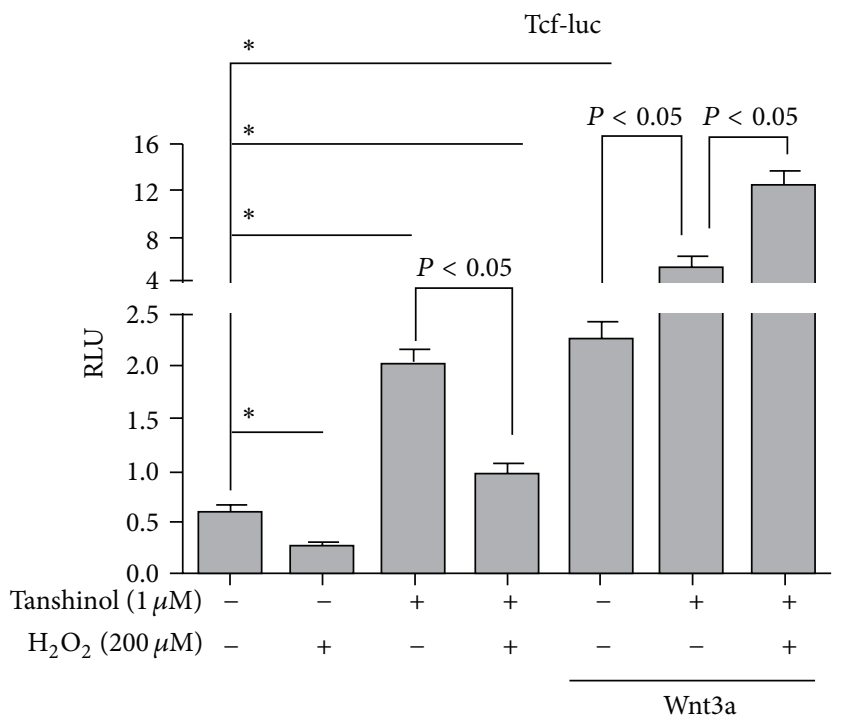

(b)

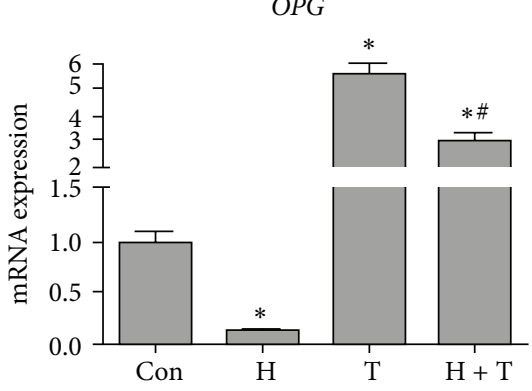

FIGURE 5: Tanshinol rescues oxidative stress-elicited inhibition of Wnt/ $\beta$-catenin signaling. (a) C2C12 cells were treated as described in Figure 4 , and protein levels of $\beta$-catenin were detected by Western Blot. Representative immunoblots were shown in upper panel. Quantitative results of relative band intensities of protein are showed in lower panel. (b) C2C12 cells were transfected with the Tcf-luc reporter plasmid or negative control. Cells transfected were treated with or without Tanshinol in the presence or absence of Wnt3a for $1 \mathrm{~h}$, followed by vehicle control, $\mathrm{H}_{2} \mathrm{O}_{2}$ for $24 \mathrm{~h}$. Luciferase activity assays were explored as described under "Section 2". The data represent mean \pm SEM of luciferase relative luminescence units (RLU) normalized to corresponding Renilla luciferase activity (triplicates). (c) C2C12 cells were treated as described in Figure 4, and the expression levels of Axin2, ALP, and OPG mRNA were quantified by qRT-PCR and normalized to GADPH mRNA. Note: (1) Con (vehicle control); (2) $\mathrm{H}\left(\mathrm{H}_{2} \mathrm{O}_{2}\right)$; (3) T (Tanshinol); (4) $\mathrm{H}+\mathrm{T}\left(\mathrm{H}_{2} \mathrm{O}_{2}+\right.$ Tanshinol); (5) $\mathrm{H}+\mathrm{R}\left(\mathrm{H}_{2} \mathrm{O}_{2}+\mathrm{Resveratrol}\right.$ ). Error bars indicate mean \pm SEM of at least three independent experiments. ${ }^{*} P<0.05$ versus vehicle control and ${ }^{\#} P<0.05$ versus $\mathrm{H}_{2} \mathrm{O}_{2}$ treatment.

in combination with Wnt3a achieves a dramatically higher level (as great as tens of times of vehicle control) under conditions of oxidative stress than that in normal conditions, exhibiting an approximate 10 -fold increase compared with vehicle control (Figure 5(b)).

To further test whether Tanshinol ameliorates the downregulation of Wnt signaling transduction under oxidative stress, we examined the mRNA expression levels of target genes of Wnt signaling in $\mathrm{C} 2 \mathrm{C} 12$ cells in response to Tanshinol under oxidative stress, using quantitative RT-PCR. As expectedly, the mRNA expression levels of Axin2, ALP and $O P G$ genes were hampered by $\mathrm{H}_{2} \mathrm{O}_{2}$ treatment, and Tanshinol antagonized the inhibitory impact of $\mathrm{H}_{2} \mathrm{O}_{2}$ on the activation of these Wnt target genes (Figure 5(c)). In brief, these lines of evidence confirm that Tanshinol reverses the inhibition of Wnt signaling under oxidative stress.

3.6. Tanshinol Blocks the Activation of FoxO3a Signaling in response to Oxidative Stress. We next asked whether Tanshinol inhibited the activation of FoxO3a-mediated transcription in response to oxidative stress. Firstly, using Western Blot, we proceeded to validate that both total FoxO3a and nuclear FoxO3a protein were activated in $\mathrm{C} 2 \mathrm{C} 12$ cells treated with $\mathrm{H}_{2} \mathrm{O}_{2}$ over a 24 hour period compared with vehicle control and that Tanshinol or Resveratrol could diminish the increase of expression levels of FoxO3a (Figure 6(a)). 
Subsequently, the capacity of Tanshinol to regulate FoxO3a pathway was monitored by using FoxO3a-luc reporter construct. While $\mathrm{H}_{2} \mathrm{O}_{2}$ stimulation is responsible for the increase of FoxO3a-luc, in line with the evidence previously mentioned [11], Tanshinol treatment alone exerted an inhibitory effect on the RLU of FoxO3a-luc for approximate one-half reduction compared with vehicle control, and counteracted the increase of FoxO3a-luc evoked by $\mathrm{H}_{2} \mathrm{O}_{2}$ in $\mathrm{C} 2 \mathrm{C} 12$ cells (Figure 6(b)). Furthermore, FoxO3a is one of the important downstream targets of the PI3K/Akt pathway in relevance to oxidative stress [43]. We further substantiated that the transcription activity of FoxO3a-luc was significantly induced by treatment with specific PI3K inhibitor LY294002 in C2C12 cells in the presence or absence of $\mathrm{H}_{2} \mathrm{O}_{2}$, and Tanshinol could block the activation of FoxO3a transcription activity triggered by LY294002 under the condition of oxidative stress.

Notwithstanding as for the putative role for the crosstalk between Canonical Wnt signaling and FoxO3a pathway under oxidative stress, we modulated $\beta$-catenin levels chemically and further examined the influence of Tanshinol on FoxO3a-luc activity. C2C12 cells are pretreated with either GSK-3 $\beta$ inhibitor $\mathrm{LiCl}$ to mimic Wnt signaling by inducing the accumulation of $\beta$-catenin, or with LRP5/LRP6 inhibitor Dkk1 protein to block Wnt signaling transduction, respectively. Consistent with previous reports [11, 18], treatment with $\mathrm{LiCl}$ enhanced FoxO3a activity in $\mathrm{C} 2 \mathrm{C} 12$ cells, while cells treated with Dkk1 showed an inhibitory effect on FoxO3a signaling (Figure 6(c)). Conversely, the increase of $\mathrm{H}_{2} \mathrm{O}_{2}$ stimulated RLU of FoxO3a-luc activity was abolished by Tanshinol regardless of blockade or activation of Wnt signaling, just as treatment with Tanshinol alone under oxidative stress (Figure 6(c)).

Based on the regulation of Tanshinol on the activation of FoxO3a transcription activity in response to oxidative stress, we ascertained the induction of mRNA expression levels of FoxO3a target genes such as Gadd45 and CAT were hindered by Tanshinol in $\mathrm{C} 2 \mathrm{C} 12$ cells under oxidative stress using qRTPCR (Figure 6(d)). In brief, the inhibitory role of Tanshinol on activation of FoxO3a pathway may be responsible for suppression of oxidative stress and involved in regulation of Wnt signaling.

3.7. Alleviation of Oxidative Stress-Elicited Wnt/Tcf Inhibition by Tanshinol Is Mediated via FoxO3a. Having elucidated the inhibitory roles of Tanshinol on activation of FoxOmediated transcription involved in regulation of the canonical Wnt signaling under oxidative stress, we examined more directly whether overexpression of $\beta$-catenin or knockdown of FoxO3a with siRNA interference could augment the influence of Tanshinol on antioxidative stress in $\mathrm{C} 2 \mathrm{C} 12$ cells and MC3T3-E1 cells. Indeed, transient knockdown of FoxO3a in the two cell lines exerted a reduction of FoxO3a transcription activity and a concomitant decrease in the mRNA expressions levels of FoxO3a target genes like Gadd45a and CAT in the presence or absence of $\mathrm{H}_{2} \mathrm{O}_{2}$ treatment (Figures 7(a), 8(a), and $8(\mathrm{c})$ ). Contrarily, activation of Tcf transcription factor and mRNA expression levels of Wnt target genes, such as Axin2 and $A L P$, showed strikingly an increase owing to knockdown of FoxO3a, and no alterations in Wnt signaling were observed in cells treated with or without $\mathrm{H}_{2} \mathrm{O}_{2}$. Encouragingly, the protective role of Tanshinol on Wnt pathway seemed more strong in cells when transfected with FoxO3a siRNA than that in cells transfected with scrambled RNA, especially in conditions of oxidative stress (Figures 7(b), 8(e) and $8(\mathrm{~g})$ ).

Having confirmed the inhibitory effect of Tanshinol on activation of FoxO3a activity in $\mathrm{C} 2 \mathrm{C} 12$ cells treated with $\mathrm{LiCl}$, we next investigated whether the activation of canonical Wnt signaling by way of $\beta$-catenin overexpression hampered FoxO-mediated transcription. As shown in Figures 7(c) and $7(\mathrm{~d})$, a similar increasing trend in both Tcf- and FoxO3amediated transcription activity was observed in the two cell lines treated with pcDNA3- $\beta$-catenin. Meanwhile, Tanshinol counteracted the decrease of Tcf transcription activity and simultaneously alleviated the increase of FoxO3a transcription activity. The previous evidence indicated that FoxO and Tcf 4 compete for interaction with $\beta$-catenin and that the interaction of FoxO with $\beta$-catenin inhibits Wnt/Tcf pathway [44]. Then, we confirmed that the transcription activity of FoxO3a was reduced to a lower level in cells treated with pcDNA3-Tcf4; in contrast, Wnt/Tcf signaling was activated by overexpression of $\mathrm{Tcf} 4$ in $\mathrm{C} 2 \mathrm{C} 12$ cells and MC3T3-E1 cells treated with or without $\mathrm{H}_{2} \mathrm{O}_{2}$ (Figures $7(\mathrm{e}$ ), 7(f), 8(b), 8(d), 8(f), and 8(h)). Taken together, these findings provide evidence that Tanshinol rescues the inhibition of Wnt $/ \beta$-catenin/Tcf signaling under oxidative stress through downregulation of FoxO3a transcription activity in $\mathrm{C} 2 \mathrm{C} 12$ cells and MC3T3-E1.

\section{Discussion}

In skeletal tissue, excessive accumulation of ROS and the subsequent activation of oxidative stress play contributory roles in the development and progression of osteoporosis $[45,46]$. Based on well-documented evidence highlighting the role of ROS production in age-related osteoporosis or in secondary osteoporosis, we confirmed herein that oxidative stress diminished osteoblastic differentiation and this might be rescued by antioxidants. Previously, we showed that a natural antioxidant of Tanshinol has the potential to promote osteoblastic differentiation, bone matrix formation, and bone mineralization and thus shows a strongly protective effect to counteract Glucocorticoid (GC)-induced osteoporosis [25], as efficiently as Resveratrol [29, 30, 47-49]. The evidence presented in this report illustrates that Tanshinol ameliorates the deleterious effects of oxidative stress on the proliferation and BMP-2-stimulated osteoblastic differentiation in $\mathrm{C} 2 \mathrm{C} 12$ cell line, a pluripotent mesenchymal precursor (Figures 2 and 3). Furthermore, we observed that the protective effect of Tanshinol is linked to relief of cell cycle arrest and counteraction of apoptosis (Figure 4). Specially, we extended the work in this study to confirmation of the protective impact of Tanshinol on osteoblastic differentiation function under conditions of oxidative stress via activation of Wnt signaling cascade and to elucidation of the capacity of Tanshinol to 


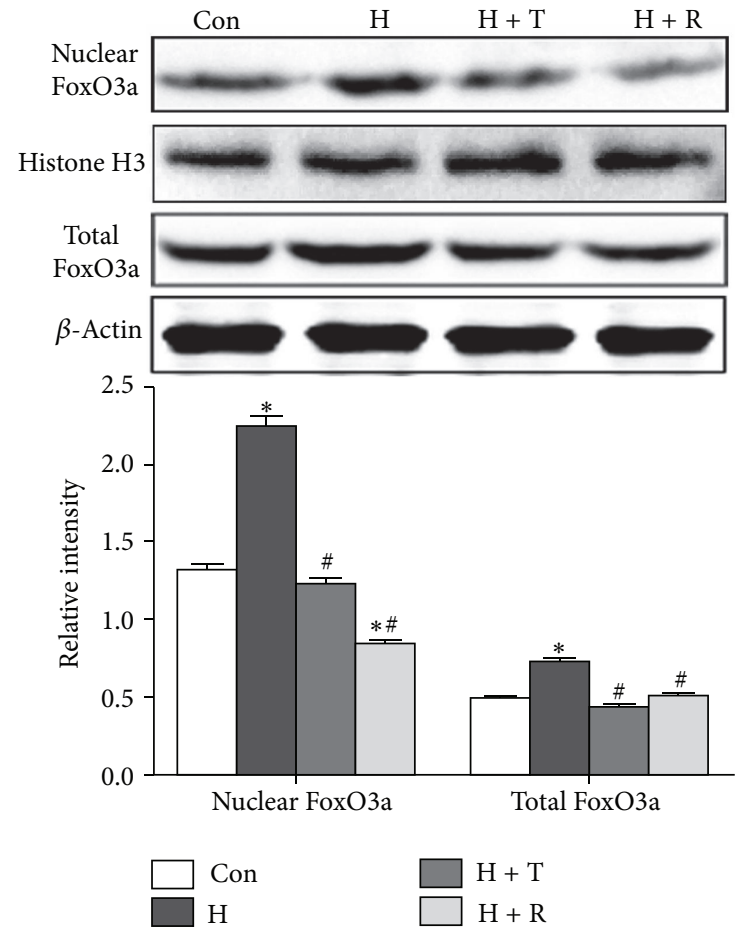

(a)

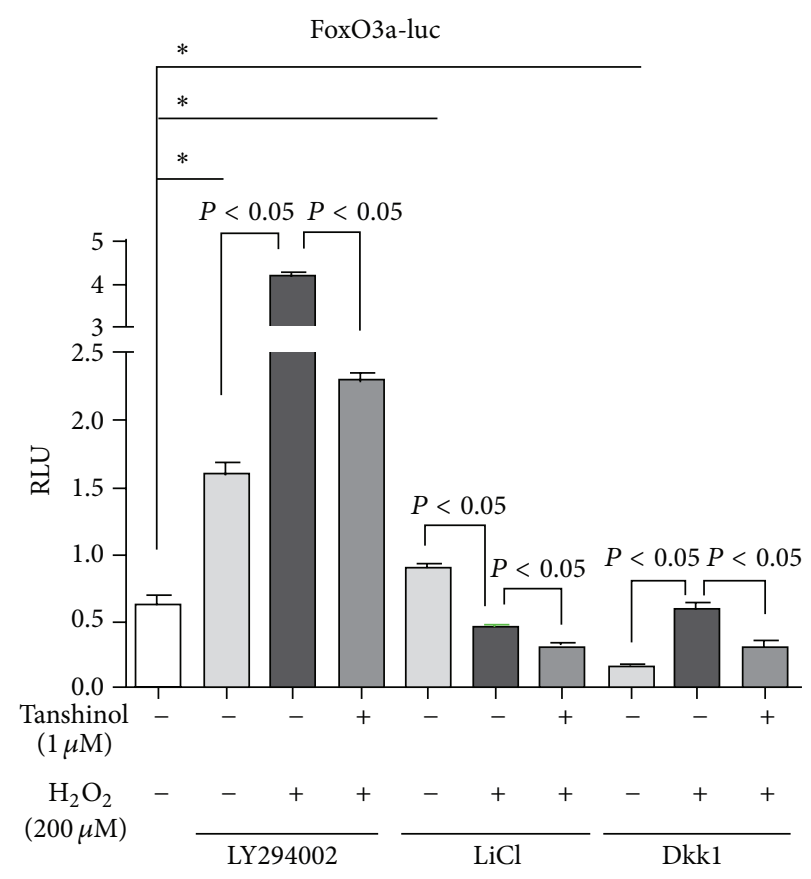

(c)

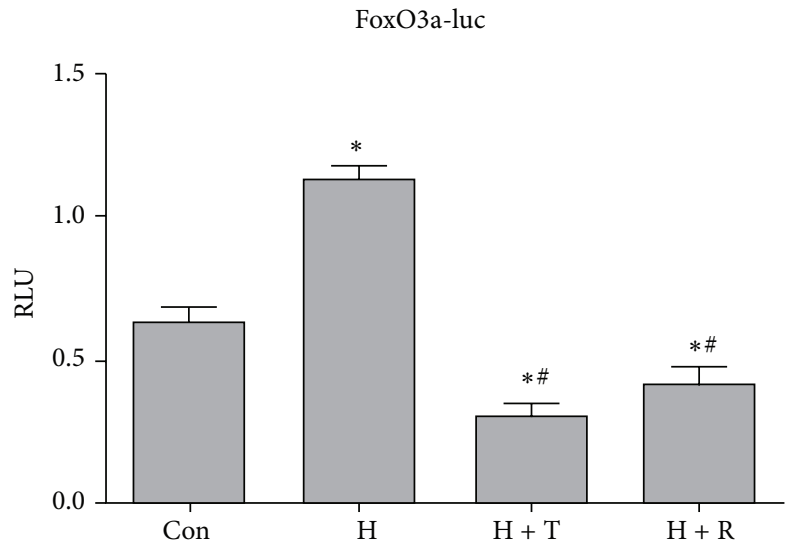

(b)
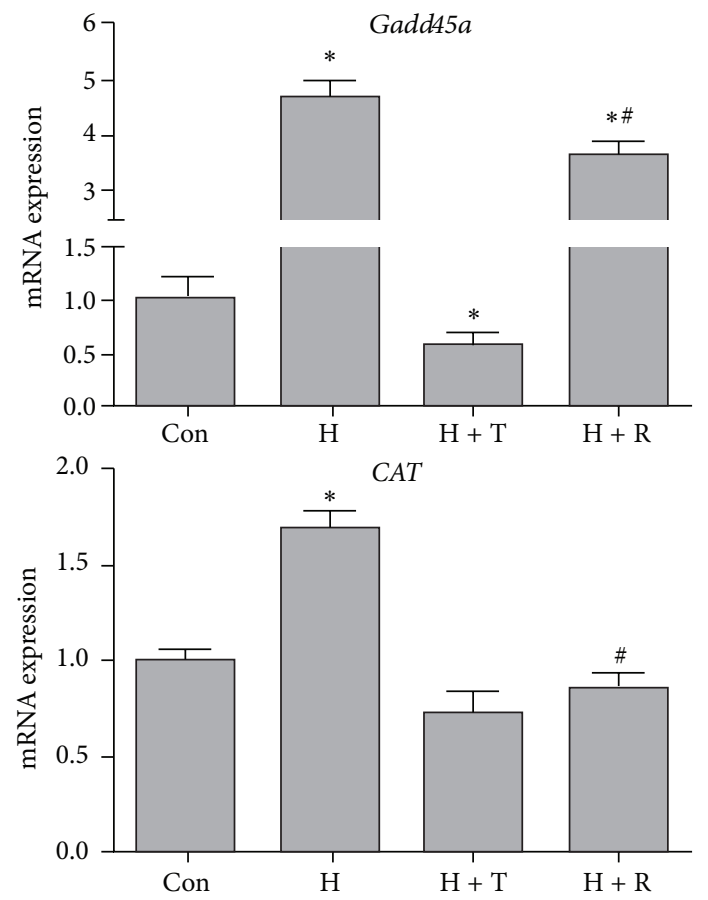

(d)

Figure 6: Tanshinol attenuates the activation of FoxO3a in response to oxidative stress. (a) $\mathrm{C} 2 \mathrm{C} 12$ cells were treated as described in Figure 4, and protein expressions from whole cell lysates and nuclear fractions were immunoblotted for FoxO3a, $\beta$-actin (whole lysates marker), and Histone H3 (nuclear marker). Representative immunoblots were shown in upper panel. Quantitative analysis of relative band intensities of protein was showed in lower panel. (b and c) Cells were transfected with the FoxO3a-luc reporter plasmid, and the treatment of Wnt3a was replaced with LY294002 $(50 \mu \mathrm{M}), \mathrm{LiCl}(10 \mathrm{mM})$, or Dkk1 $(500 \mathrm{ng} / \mathrm{mL})$, and other procedures of experiments were addressed as described in Figure 5(b). (d) C2C12 cells were treated as described in Figure 4, and the expression levels of Gadd45 and CAT mRNA were quantified by qRT-PCR and normalized to GADPH mRNA. Note: (1) Con (vehicle control); (2) $\mathrm{H}\left(\mathrm{H}_{2} \mathrm{O}_{2}\right)$; (3) T (Tanshinol); (4) $\mathrm{H}+\mathrm{T}\left(\mathrm{H}_{2} \mathrm{O}_{2}+\mathrm{Tanshinol}\right.$ ); (5) $\mathrm{H}+\mathrm{R}\left(\mathrm{H}_{2} \mathrm{O}_{2}+\right.$ Resveratrol). Error bars indicate mean $\pm \mathrm{SEM}$ of at least three independent experiments. ${ }^{*} P<0.05$ versus vehicle control and ${ }^{\#} P<0.05$ versus $\mathrm{H}_{2} \mathrm{O}_{2}$ treatment. 


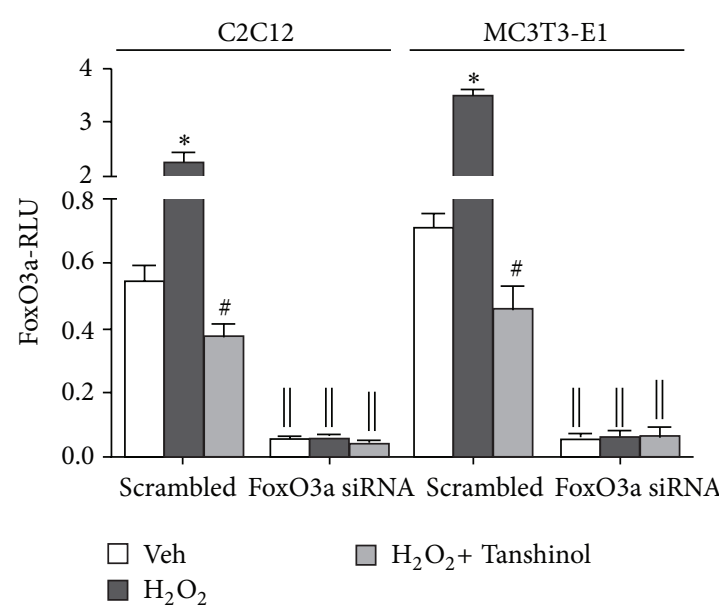

(a)

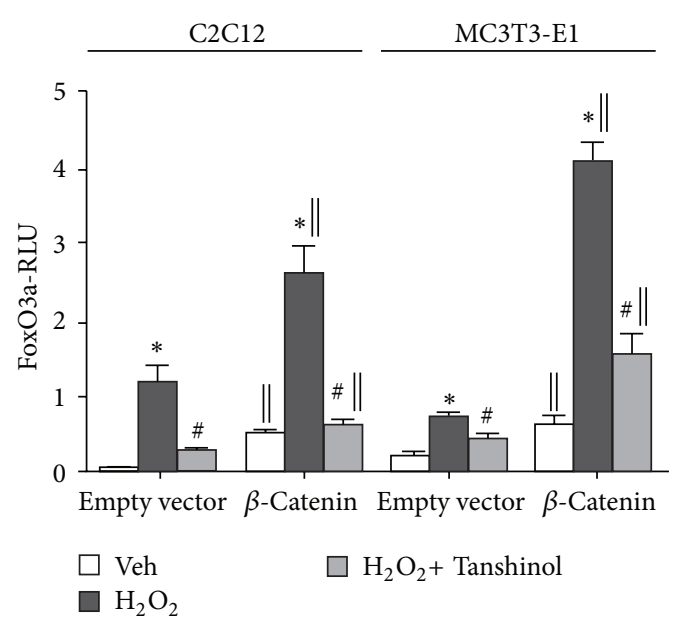

(c)

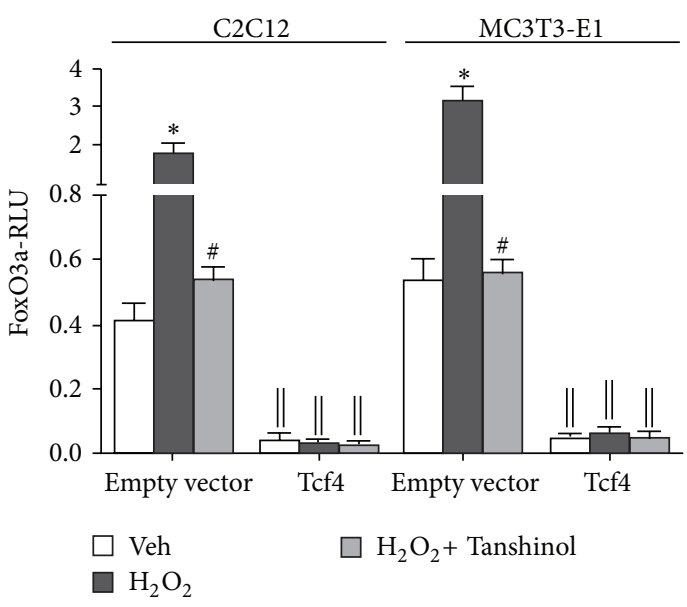

(e)

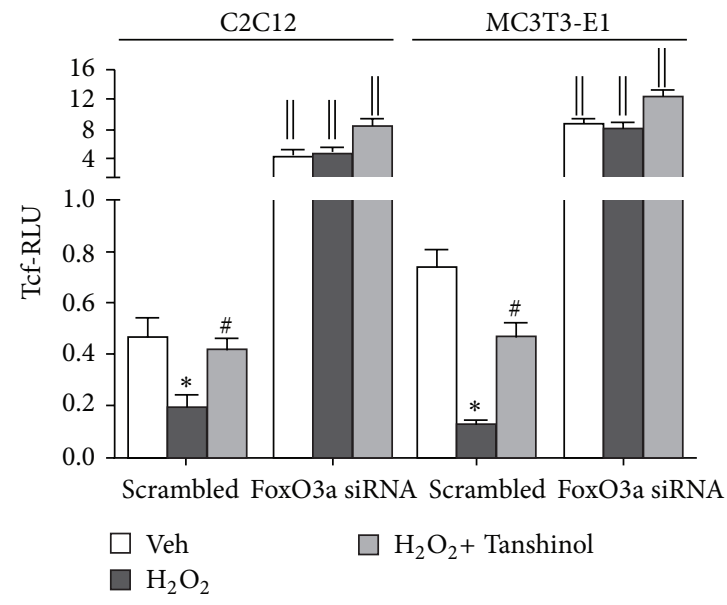

(b)

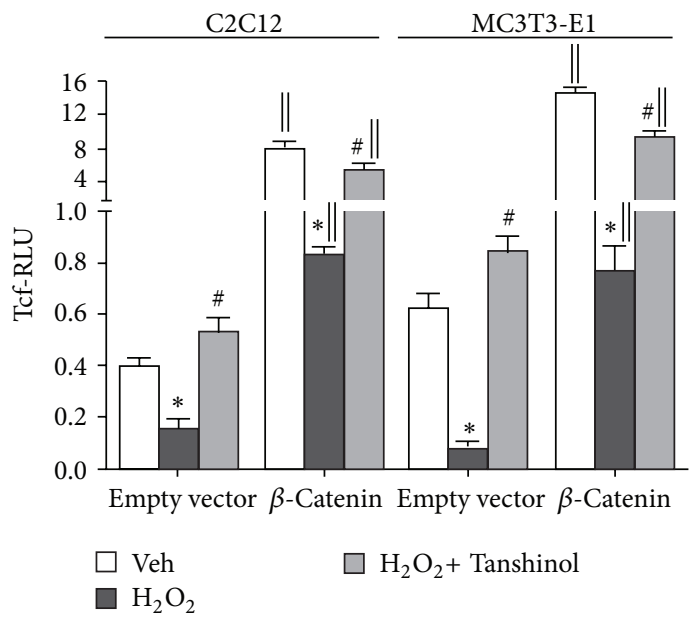

(d)

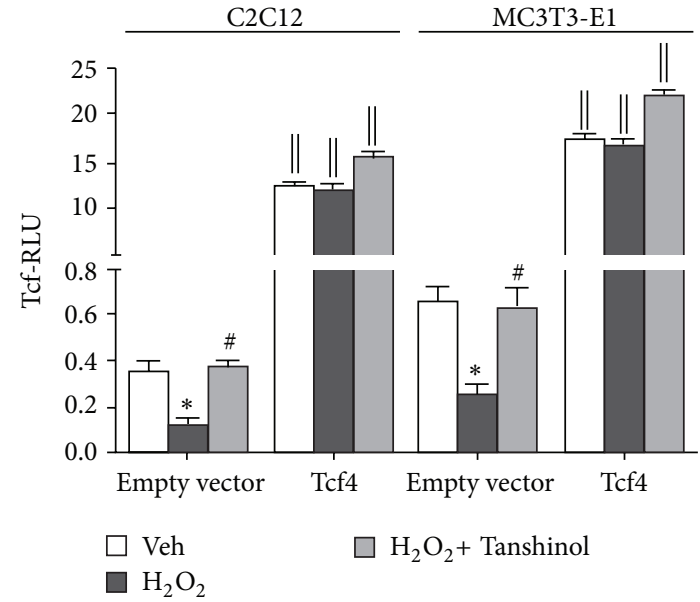

(f)

FIgURE 7: Effects of Tanshinol on Tcf- and FoxO3a-mediated transcription activity in C2C12 cells and MC3T3-E1 cells treated with FoxO3a siRNA, or with overexpression of $\beta$-Catenin or Tcf4 under oxidative stress. ((a), (c), and (e)) C2C12 cells or MC3T3-E1 cells were cotransfected with the FoxO3a-luc reporter plasmid in combination with FoxO3a siRNA, or pcDNA3- $\beta$-catenin, or pcDNA3-Tcf4, or corresponding control using Attractene transfection reagent. Other procedures were carried out as described in Figure 5(b). ((b), (d), and (f)) Cells were cotransfected with Tcf-luc reporter plasmid and other treatment described in (a), (c), and (e). Others procedure were made as described in Figure 5(b). Bars indicate mean \pm SME of triplicate determinations. ${ }^{*} P<0.05$ versus vehicle control and ${ }^{\#} P<0.05$ versus $\mathrm{H}_{2} \mathrm{O}_{2}$ treatment; $\|_{P}<0.05$ versus corresponding empty vector or scrambled control. 


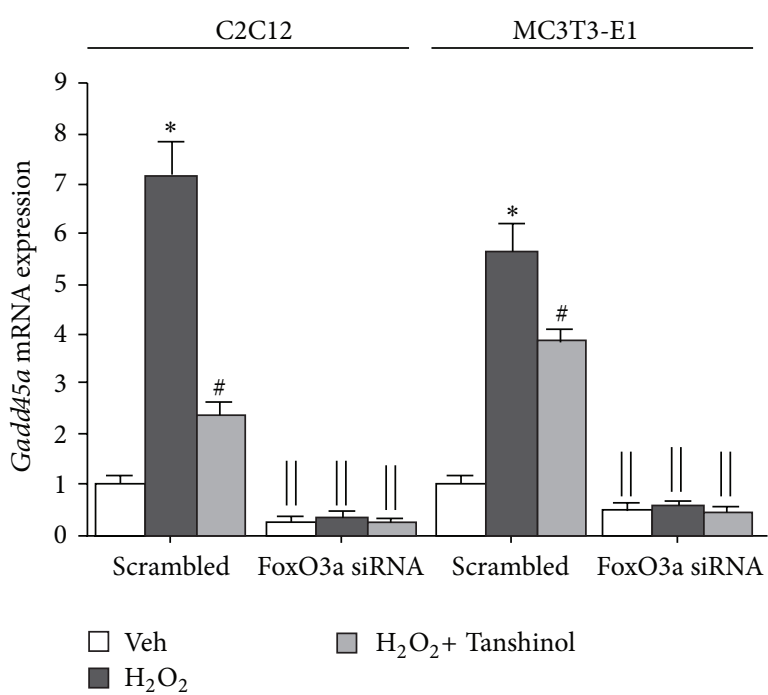

(a)

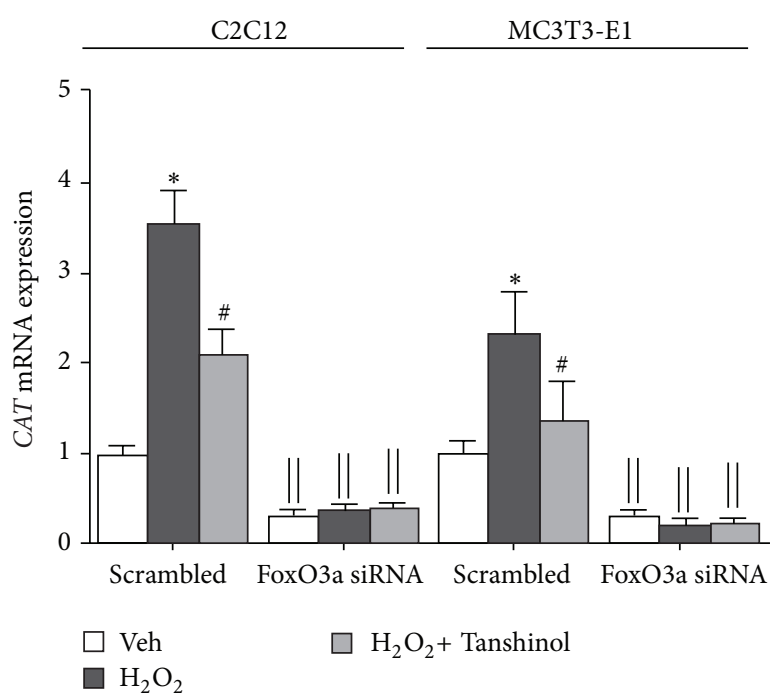

(c)

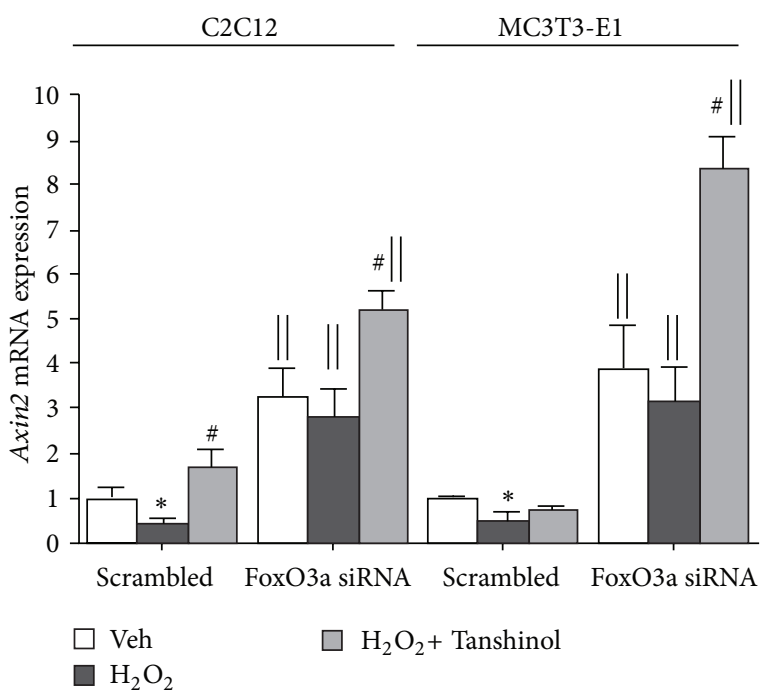

(e)

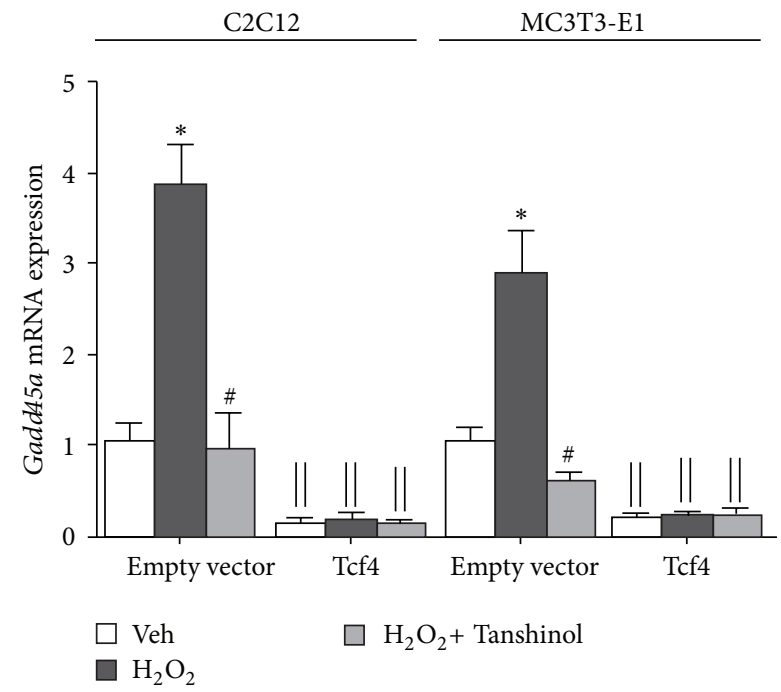

(b)

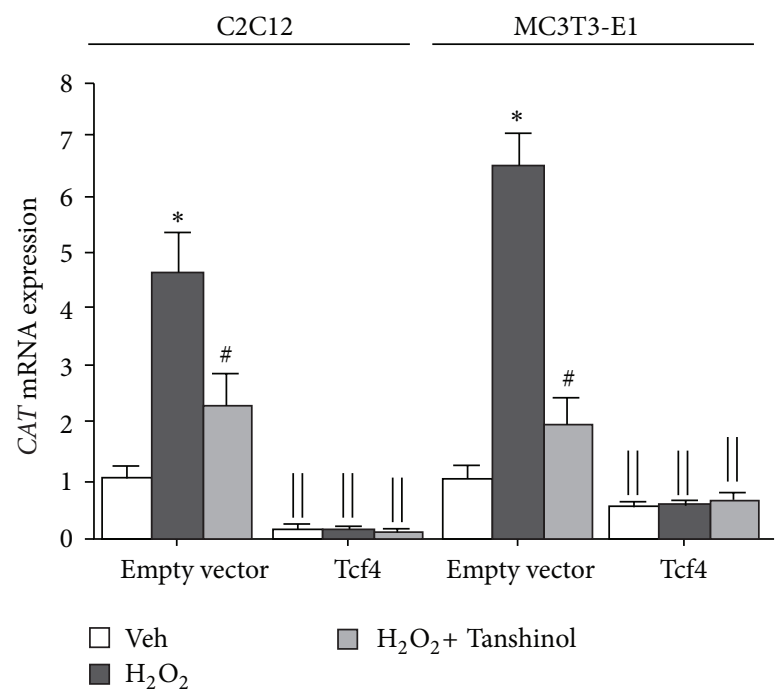

(d)

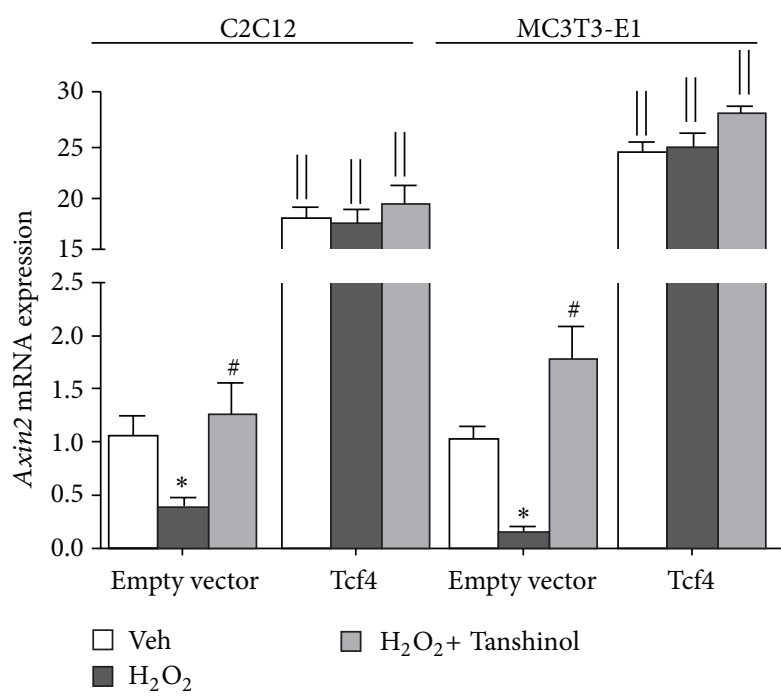

(f)

FIGURE 8: Continued. 


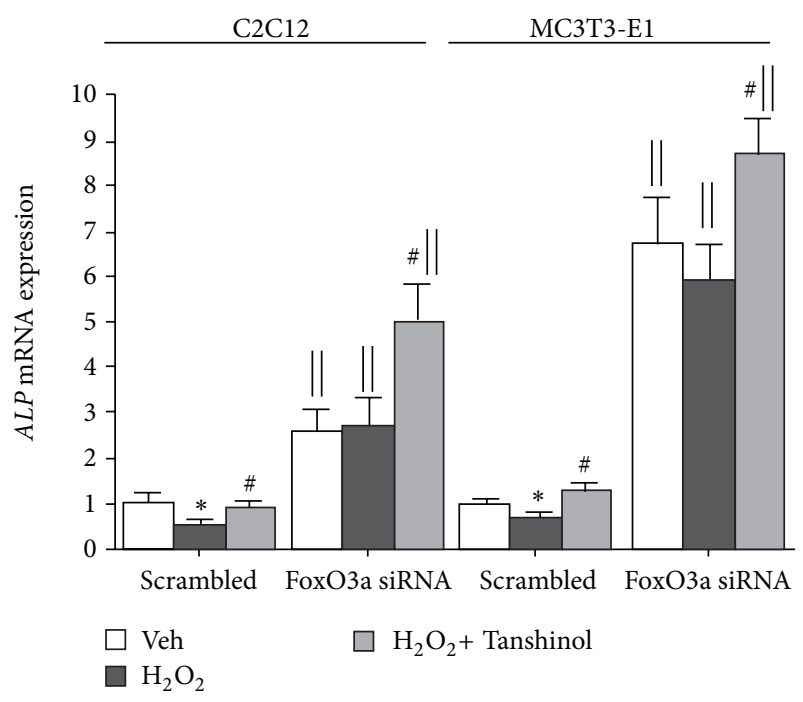

(g)

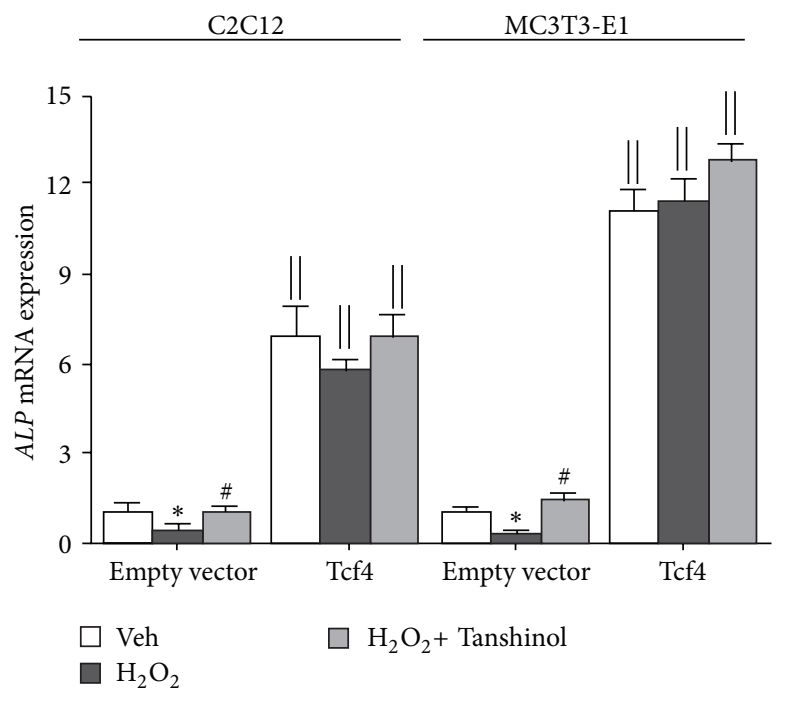

(h)

Figure 8: Effects of Tanshinol on targets genes of Wnt/Tcf and FoxO3a in C2C12 cells and MC3T3-E1 cells treated with FoxO3a siRNA, or with Tcf4 overexpression under oxidative stress. ((a), (c), (e), and (g)) C2C12 cells or MC3T3-E1 cells were transfected transiently with either the FoxO3a siRNA or the scrambled RNA control in the presence or absence of vehicle, $\mathrm{H}_{2} \mathrm{O}_{2}$, or Tashinol for 24 hours. The relative mRNA expression levels of Gadd45a, CAT, Axin2, and ALP genes in control cells (Scrambled) and in the FoxO3a-knockdown (FoxO3a siRNA) cells were assessed by quantitative RT-PCR assay. ((b), (d), (f), and (h)) C2C12 cells or MC3T3-E1 cells were transfected transiently with either the overexpression plasmid of Tcf4 or the empty vector control. The following procedure was executed as described in (a), (c), (e), and (g). mRNA values were normalized to GAPDH mRNA. Bars represent mean \pm SME of three independent experiments. ${ }^{*} P<0.05$ versus vehicle control and ${ }^{\#} P<0.05$ versus $\mathrm{H}_{2} \mathrm{O}_{2}$ treatment; ${ }^{\|} P<0.05$ versus corresponding empty vector or scrambled control.

cope with oxidative stress through suppression of FoxO3a transcription factor (Figures 5, 6, 7, and 8).

Tanshinol is one of polyphenolic acid components isolated from Salvia miltiorrhiza Bunge, and its chemical structure consists of several polyphenolic hydroxyl groups (Figure 2(c)), just like Resveratrol [50], which contributes to the suppression of oxidative stress via regulation of FoxO3a transcription factor $[31,32,51]$. What are the underlying mechanisms whereby Tanshinol protects against oxidative stress in the process of osteoblastic differentiation? Based on the results of the present study and previous reports, there are at least several plausible mechanisms. To begin with, the findings from our study show that $\mathrm{H}_{2} \mathrm{O}_{2}$ provokes the increase in oxidative stress and subsequently resulted in the decrease in cell viability, which is consistent with previous work of the others (Figure 2) [52]. Moreover, the further evidence presented in this report demonstrates that the apoptotic response is observed morphologically and the activation of caspase-3 reveals an underlying mechanism of cell death in a caspase-3-dependent manner during the process of apoptosis (Figure 3). As is well known, the extrinsic and intrinsic pathways of apoptosis principally converge in the caspase cascade by the activation of downstream effector caspase-3, which is initiated by oxidative stress to transform into cleaved caspase- 3 and then exert the effect in the last stage of cell death, including cellular shrinkage, cellular membrane phosphatidylserine (PS) exposure, DNA fragmentation, and eventually apoptosis [53, 54]. Additionally, active caspase-3 has the capacity to cleave Akt, leading to the inhibition of the PI3K/Akt signaling pathway, which in turn relocates FoxOs proteins back into the nucleus to activate transcriptional activity and induces simultaneously cell cycle arrest and apoptosis $[55,56]$. Briefly, our data suggest a molecular mechanism that the preventive effects of Tanshinol on cell cycle arrest and apoptosis induction initiated by ROS may be associated with regulation of the caspase-3/FoxO3a pathway under oxidative stress. Future investigation is needed to address the question of how Tanshinol downregulates caspase-3/FoxO3a pathway cascade to abrogate the activation of apoptosis, which helps to shed light on our understanding of the protective role of Tanshinol on osteoblastic differentiation under conditions of activation of FoxO3a in cellular responses to oxidative stress.

The evidence in the present study indicates that Tanshinol contributes to the suppression of the deleterious impacts of oxidative stress on osteoblastic differentiation in $\mathrm{C} 2 \mathrm{C} 12$ cells stimulated by BMP-2. Previous studies have shown that BMPs comprise a subfamily within the TGF- $\beta$ superfamily and exert an important role in skeletal development and adult bone homeostasis [57]. Consistent with the previous findings [58], continuous BMP-2 exposure converts the differentiation switch of $\mathrm{C} 2 \mathrm{C} 12$ myoblasts into osteoblast lineage cells (Figure 3). Furthermore, treatment with Tanshinol ameliorates the decline of osteogenic differentiation in $\mathrm{C} 2 \mathrm{C} 12$ cells stimulated by BMP-2 under oxidative stress. Evidence of in vitro studies previously implied that $\beta$-catenin is a required downstream factor of BMP-2 for osteoblast mineralization by the way of a Wnt autocrine loop [59]. Our 
findings indicate that treatment with Tanshinol in $\mathrm{C} 2 \mathrm{C} 12$ cells contributes to the upregulation of Wnt signaling. Taken together, the findings in this study suggest that Tanshinol may be conducive to osteoblastic differentiation under oxidative stress via Wnt/BMP-2 pathway cascade.

Although it is well accepted that oxidative stress stimulates the activation of FoxO3a signaling pathway and subsequently leads to its competition with Tcf protein for the association with the limited pool of $\beta$-catenin, the interactions between oxidative stress and the Wnt signaling pathway remain controversial. Several lines of evidence support the functional role of oxidative stress in the downregulation of Wnt pathway in A14, C2C12, OB-6, and/or HEK293 cells $[11,18,60]$, other researchers, however, have an opposite notion that oxidative stress contributes to activation of the Wnt/ $\beta$-catenin pathway and downstream Tcf signaling in L cells, NIH3T3 or HEK293 cells [61], endothelial cells [62], and a rat model of diabetic retinopathy [63, 64]. Herein, different from the evidence mentioned above, results from our experiments in C2C12 cells and MC3T3-E1 cells have supported that Wnt pathway downstream Tcf signaling is suppressed by oxidative stress, and antioxidant Tanshinol reverses the dysregulation of $\mathrm{Tcf}$ transcription activities. The finding is similar to our previously established work that Tanshinol inhibits Dkk1 mRNA level and stimulates the expression of $\beta$-catenin and Runx 2 in the process of rat marrow stromal cell differentiation with or without GC treatment [26]. However, Tcf signaling pathway is activated dramatically by oxidative stress in C2C12 cells in the presence of a combination of Wnt3a and Tanshinol, approximately 4fold higher than that without oxidative stress. It may be that Tanshinol upregulates Wnt pathway cascade synergistically with Wnt3a to ameliorate deleterious effects of oxidant on the function of cells under oxidative stress.

The discrepancy between the results of this opposite evidence and ours may be due to the different experimental design and may be lie in different mechanisms. One causative role in the positive effect of oxidative stress in the presence of exogenous Wnt3a on the activation of Wnt signaling may be associated with endogenous nucleoredoxin (NRX), which acts as a suppressor of $\mathrm{Wnt} / \beta$-catenin signaling by the association with disheveled (Dvl), and the complex between Dvl and NRX is impaired feasibly by the oxidation like $\mathrm{H}_{2} \mathrm{O}_{2}$ treatment, leading to the activation of Wnt signal cascade from receptor Frizzled to Tcf transcription factor [61]. Another reason of the activation of Wnt pathway under oxidative stress may originate from the stabilization of Wnt receptor of LRP6 and the increase of LRP6 level caused by oxidant, such as $\mathrm{H}_{2} \mathrm{O}_{2}$ [64].

Eventually, the evidence indicated that either FoxO3a siRNA or overexpression of Tcf4 shows the similar influence on the activation of Wnt signaling and suppression of FoxO3a transcription activity in $\mathrm{C} 2 \mathrm{C} 12$ cells and MC3T3E1 cells treated with or without oxidant stimulus. Both Tcfand FoxO3a-mediated transcription activities, however, are elevated by virtue of overexpression of $\beta$-catenin in cells under oxidative stress. As reported previously [18, 44], it is vital for cells to diverge from Tcf to FoxO3a under conditions of oxidative stress, and a role for $\beta$-catenin in the regulation of resistance against oxidative stress has been highlighted in these studies. There is a disagreement between the previous evidence and the observations reported here. A more intriguing and possible explanation for this difference could reside within the present fact that it is not $\beta$-catenin protein for counteraction the activation of FoxO3a transcription factor under oxidative stress, but Tcf transcription factor. Therefore, the suppression of activation of FoxO3a contributes to antagonizing inhibitory effect of oxidative stress on Wnt/Tcf pathway that may be dependent on the competency of Wnt signaling. Interestingly, it seems that Tanshinol exerts no effect on FoxO3a activity or Wnt signaling in cells under conditions of FoxO3a siRNA interference or Tcf4 overexpression. Meanwhile, a dual ameliorating influence of Tanshinol on activation of FoxO3a-mediated transcription and inhibition of Tcf-mediated transcription is observed in cells under oxidative stress. Further research should be required to address and expand the present findings in vivo.

In summary, we have provided herein a novel feasible molecular explanation of Tanshinol in counteracting the inhibitory effect of oxidative stress on osteoblastic differentiation. These results strongly support the viewpoint that Tanshinol scavenges ROS and subsequently attenuates oxidative stress, resulting in downregulation of $\mathrm{FoxO} 3$ a signal responsible for caspase-3-dependent apoptosis and cell cycle arrest. Moreover, Tanshinol upregulates Wnt signal cascade that is achieved by increasing activity of Tcf transcription factors for osteoblastic differentiation under oxidative stress. Our findings suggest that the beneficial effects of Tanshinol may be developed as a novel therapeutic approach in recently recognized conditions of niche targeting osteoporosis. Actually, Tanshinol used as a principal active ingredient of approved drug for the treatment of cardiovascular diseases for ten years in China, further studies will be needed to investigate whether it may be a candidate for prevention and therapeutic applications in osteoporosis through manipulation of the Wnt/FoxO3a pathway in bone tissue.

\section{Conflict of Interests}

All authors state that they have nothing to disclose and no conflict of interests.

\section{Acknowledgments}

This study was supported by grants-in-aid from the National Natural Science Foundation of China (Grant no. 81273518), the Science \& Technology Innovation Fund of Guangdong Medical College (STIF201104), and the Natural Science Foundation of Guangdong Province (S2011020005206 and 2012B060300027). Yajun Yang contributed to the conception and design, was involved in acquisition of data, data analysis and interpretation, and drafting and revising paper, and approved of the final version. Yanjie Su, Dongtao Wang and Yahui Chen were involved in acquisition of data and revision of paper and approved the final version. Tie $\mathrm{Wu}$ was involved in data analysis and drafting and approved of the final version. Liao Cui, Xuegang Sun, and Gang Li 
contributed to the conception and design, data interpretation and drafting and revising paper and approved of the final version. Liao Cui and Xuegang Sun accept responsibility for the integrity of the data analysis.

\section{References}

[1] M. Abdollahi, B. Larijani, R. Rahimi, and P. Salari, "Role of oxidative stress in osteoporosis," Therapy, vol. 2, no. 5, pp. 787796, 2005.

[2] S. C. Manolagas, "From estrogen-centric to aging and oxidative stress: a revised perspective of the pathogenesis of osteoporosis," Endocrine Reviews, vol. 31, no. 3, pp. 266-300, 2010.

[3] M. Almeida, "Unraveling the role of FoxOs in bone-Insights from mouse models," Bone, vol. 49, no. 3, pp. 319-327, 2011.

[4] S. L. Hui, C. W. Slemenda, and C. C. Johnston Jr., "Age and bone mass as predictors of fracture in a prospective study," The Journal of Clinical Investigation, vol. 81, no. 6, pp. 1804-1809, 1988.

[5] S. E. Painter, M. Kleerekoper, and P. M. Camacho, "Secondary osteoporosis: a review of the recent evidence," Endocrine Practice, vol. 12, no. 4, pp. 436-445, 2006.

[6] Y. Suzuki, "Secondary osteoporosis. A review of recent evidence focusing on glucocorticoid-induced osteoporosis and osteoporosis associated with rheumatoid arthritis," Clinical calcium, vol. 17, no. 1, pp. 104-107, 2007.

[7] P. Salari and M. Abdollahi, "A comprehensive review of the shared roles of inflammatory cytokines in osteoporosis and cardiovascular diseases as two common old people problem; actions toward development of new drugs," International Journal of Pharmacology, vol. 7, no. 5, pp. 552-567, 2011.

[8] M.-T. Rached, A. Kode, L. Xu et al., "FoxO1 is a positive regulator of bone formation by favoring protein synthesis and resistance to oxidative stress in osteoblasts," Cell Metabolism, vol. 11, no. 2, pp. 147-160, 2010.

[9] F. L. Muller, M. S. Lustgarten, Y. Jang, A. Richardson, and H. Van Remmen, "Trends in oxidative aging theories," Free Radical Biology and Medicine, vol. 43, no. 4, pp. 477-503, 2007.

[10] M. Almeida, L. Han, E. Ambrogini, R. S. Weinstein, and S. C. Manolagas, "Glucocorticoids and tumor necrosis factor $\alpha$ increase oxidative stress and suppress Wnt protein signaling in osteoblasts," The Journal of Biological Chemistry, vol. 286, no. 52, pp. 44326-44335, 2011.

[11] M. Almeida, L. Han, M. Martin-Millan, C. A. O’Brien, and S. C. Manolagas, "Oxidative stress antagonizes Wnt signaling in osteoblast precursors by diverting $\beta$-catenin from $\mathrm{T}$ cell factor- to forkhead box O-mediated transcription," The Journal of Biological Chemistry, vol. 282, no. 37, pp. 27298-27305, 2007.

[12] F. Wauquier, L. Leotoing, V. Coxam, J. Guicheux, and Y. Wittrant, "Oxidative stress in bone remodelling and disease," Trends in Molecular Medicine, vol. 15, no. 10, pp. 468-477, 2009.

[13] M. Kassem and P. J. Marie, "Senescence-associated intrinsic mechanisms of osteoblast dysfunctions," Aging Cell, vol. 10, no. 2, pp. 191-197, 2011.

[14] I. R. Garrett, B. F. Boyce, R. O. C. Oreffo, L. Bonewald, J. Poser, and G. R. Mundy, "Oxygen-derived free radicals stimulate osteoclastic bone resorption in rodent bone in vitro and in vivo," The Journal of Clinical Investigation, vol. 85, no. 3, pp. 632-639, 1990.

[15] N. Suda, I. Morita, T. Kuroda, and S.-I. Murota, "Participation of oxidative stress in the process of osteoclast differentiation," Biochimica et Biophysica Acta, vol. 1157, no. 3, pp. 318-323, 1993.
[16] C. Galli, G. Passeri, and G. M. Macaluso, "FoxOs, Wnts and oxidative stress-induced bone loss: New players in the periodontitis arena?" Journal of Periodontal Research, vol. 46, no. 4, pp. 397-406, 2011.

[17] E. Ambrogini, M. Almeida, M. Martin-Millan et al., "FoxOmediated defense against oxidative stress in osteoblasts is indispensable for skeletal homeostasis in mice," Cell Metabolism, vol. 11, no. 2, pp. 136-146, 2010.

[18] M. A. G. Essers, L. M. M. De Vries-Smits, N. Barker, P. E. Polderman, B. M. T. Burgering, and H. C. Korswagen, "Functional interaction between $\beta$-catenin and FOXO in oxidative stress signaling," Science, vol. 308, no. 5725, pp. 1181-1184, 2005.

[19] B. Östman, K. Michaëlsson, J. Helmersson et al., "Oxidative stress and bone mineral density in elderly men: antioxidant activity of alpha-tocopherol," Free Radical Biology and Medicine, vol. 47, no. 5, pp. 668-673, 2009.

[20] A. Arslan, S. Orkun, G. Aydin et al., "Effects of ovariectomy and ascorbic acid supplement on oxidative stress parameters and bone mineral density in rats," Libyan Journal of Medicine, vol. 6, no. 1, pp. 1-9, 2011.

[21] J. Liu, C.-F. Yang, B.-L. Lee, H.-M. Shen, S.-G. Ang, and C. N. Ong, "Effect of Salvia miltiorrhiza on aflatoxin B1-induced oxidative stress in cultured rat hepatocytes," Free Radical Research, vol. 31, no. 6, pp. 559-568, 1999.

[22] L. Wu, H. Qiao, Y. Li, and L. Li, "Protective roles of puerarin and Danshensu on acute ischemic myocardial injury in rats," Phytomedicine, vol. 14, no. 10, pp. 652-658, 2007.

[23] J.-Y. Han, Y. Horie, J.-Y. Fan et al., "Potential of 3,4-dihydroxyphenyl lactic acid for ameliorating ischemia-reperfusioninduced microvascular disturbance in rat mesentery," American Journal of Physiology, vol. 296, no. 1, pp. G36-G44, 2009.

[24] B.-L. Zhao, W. Jiang, Y. Zhao, J.-W. Hou, and W.-J. Xin, "Scavenging effects of Salvia miltiorrhiza on free radicals and its protection for myocardial mitochondrial membranes from ischemia-reperfusion injury," Biochemistry and Molecular Biology International, vol. 38, no. 6, pp. 1171-1182, 1996.

[25] L. Cui, Y.-Y. Liu, T. Wu, C.-M. Ai, and H.-Q. Chen, "Osteogenic effects of $\mathrm{D}+\beta-3,4$-dihydroxyphenyl lactic acid (salvianic acid A, SAA) on osteoblasts and bone marrow stromal cells of intact and prednisone-treated rats," Acta Pharmacologica Sinica, vol. 30, no. 3, pp. 321-332, 2009.

[26] L. Cui, T. Li, Y. Liu et al., "Salvianolic acid b prevents bone loss in prednisone-treated rats through stimulation of osteogenesis and bone marrow angiogenesis," PLoS ONE, vol. 7, no. 4, Article ID e34647, 2012.

[27] P. S. Sharif, S. Nikfar, and M. Abdollahi, "Prevention of bone resorption by intake of phytoestrogens in postmenopausal women: a meta-analysis," Age, vol. 33, no. 3, pp. 421-431, 2011.

[28] S. Rayalam, M. A. Della-Fera, and C. A. Baile, "Synergism between resveratrol and other phytochemicals: implications for obesity and osteoporosis," Molecular Nutrition and Food Research, vol. 55, no. 8, pp. 1177-1185, 2011.

[29] K. Mizutani, K. Ikeda, Y. Kawai, and Y. Yamori, "Resveratrol attenuates ovariectomy-induced hypertension and bone loss in stroke-prone spontaneously hypertensive rats," Journal of Nutritional Science and Vitaminology, vol. 46, no. 2, pp. 78-83, 2000.

[30] Z. Dai, Y. Li, L. D. Quarles et al., "Resveratrol enhances proliferation and osteoblastic differentiation in human mesenchymal stem cells via ER-dependent ERK1/2 activation," Phytomedicine, vol. 14, no. 12, pp. 806-814, 2007. 
[31] G. Li, C. Luna, I. D. Navarro et al., "Resveratrol prevention of oxidative stress damage to lens epithelial cell cultures is mediated by forkhead box O activity," Investigative Ophthalmology \& Visual Science, vol. 52, no. 7, pp. 4395-4401, 2011.

[32] J.-L. Su, C.-Y. Yang, M. Zhao, M.-L. Kuo, and M.-L. Yen, "Forkhead proteins are critical for bone morphogenetic protein2 regulation and anti-tumor activity of resveratrol," The Journal of Biological Chemistry, vol. 282, no. 27, pp. 19385-19398, 2007.

[33] Y. Li, L. Shen, R. Chen et al., "Effects of Salivae Miltiorrhizae Liguspyragine Hydrochloride and Glucose Injection on the levels of main platelet thrombin receptors in chronic haemodialysis patients," Chinese journal of integrative medicine, vol. 17, no. 8, pp. 625-630, 2011.

[34] C. Higuchi, N. Nakamura, H. Yoshikawa, and K. Itoh, "Transient dynamic actin cytoskeletal change stimulates the osteoblastic differentiation," Journal of Bone and Mineral Metabolism, vol. 27, no. 2, pp. 158-167, 2009.

[35] A. Ferlin, L. Perilli, L. Gianesello, G. Taglialavoro, and C. Foresta, "Profiling insulin like factor 3 (INSL3) signaling in human osteoblasts," PLoS ONE, vol. 6, no. 12, Article ID e29733, 2011.

[36] M. K. Henry, J. T. Lynch, A. K. Eapen, and F. W. Quelle, "DNA damage-induced cell-cycle arrest of hematopoietic cells is overridden by activation of the PI-3 kinase/Akt signaling pathway," Blood, vol. 98, no. 3, pp. 834-841, 2001.

[37] Y. Yan, J. C. Bian, L. X. Zhong, Y. Zhang, Y. Sun, and Z. P. Liu, "Oxidative stress and apoptotic changes of rat cerebral cortical neurons exposed to cadmium in vitro," Biomedical and Environmental Sciences, vol. 25, no. 2, pp. 172-181, 2012.

[38] S. Burattini, S. Salucci, V. Baldassarri et al., "Anti-apoptotic activity of hydroxytyrosol and hydroxytyrosyl laurate," Food and Chemical Toxicology, vol. 55, pp. 248-256, 2013.

[39] S. Yamada, M. Taniguchi, M. Tokumoto et al., "The antioxidant tempol ameliorates arterial medial calcification in uremic rats: important role of oxidative stress in the pathogenesis of vascular calcification in chronic kidney disease," Journal of Bone and Mineral Research, vol. 27, no. 2, pp. 474-485, 2012.

[40] Y. C. Shang, Z. Z. Chong, J. Hou, and K. Maiese, "Wnt1, FoxO3a, and NF- $\kappa \mathrm{B}$ oversee microglial integrity and activation during oxidant stress," Cellular Signalling, vol. 22, no. 9, pp. 1317-1329, 2010.

[41] S. Ganesan, B. L. Unger, A. T. Comstock et al., "Aberrantly activated EGFR contributes to enhanced IL-8 expression in COPD airways epithelial cells via regulation of nuclear FoxO3A," Thorax, vol. 68, no. 2, pp. 131-141, 2013.

[42] J. L. Brubacher and N. C. Bols, "Chemically de-acetylated 2/,7Idichlorodihydrofluorescein diacetate as a probe of respiratory burst activity in mononuclear phagocytes," Journal of Immunological Methods, vol. 251, no. 1-2, pp. 81-91, 2001.

[43] D. Accili and K. C. Arden, "FoxOs at the crossroads of cellular metabolism, differentiation, and transformation," Cell, vol. 117, no. 4, pp. 421-426, 2004.

[44] D. Hoogeboom, M. A. G. Essers, P. E. Polderman, E. Voets, L. M. M. Smits, and B. M. T. Burgering, "Interaction of FOXO with $\beta$-catenin inhibits $\beta$-catenin/T cell factor activity," The Journal of Biological Chemistry, vol. 283, no. 14, pp. 9224-9230, 2008.

[45] H. J. Kim, E.-J. Chang, H.-M. Kim et al., "Antioxidant $\alpha$-lipoic acid inhibits osteoclast differentiation by reducing nuclear factor- $\kappa \mathrm{B}$ DNA binding and prevents in vivo bone resorption induced by receptor activator of nuclear factor- $\kappa \mathrm{B}$ ligand and tumor necrosis factor- $\alpha$," Free Radical Biology and Medicine, vol. 40, no. 9, pp. 1483-1493, 2006.
[46] X.-C. Bai, D. Lu, J. Bai et al., "Oxidative stress inhibits osteoblastic differentiation of bone cells by ERK and NF- $\kappa \mathrm{B}$," Biochemical and Biophysical Research Communications, vol. 314, no. 1, pp. 197-207, 2004.

[47] C.-M. Bäckesjö, Y. Li, U. Lindgren, and L.-A. Haldosén, “Activation of Sirtl decreases adipocyte formation during osteoblast differentiation of mesenchymal stem cells," Journal of Bone and Mineral Research, vol. 21, no. 7, pp. 993-1002, 2006.

[48] T. Uysal, S. Gorgulu, A. Yagci, Y. Karslioglu, O. Gunhan, and D. Sagdic, "Effect of resveratrol on bone formation in the expanded inter-premaxillary suture: early bone changes," Orthodontics and Craniofacial Research, vol. 14, no. 2, pp. 80-87, 2011.

[49] S. M. Durbin, J. R. Jackson, M. J. Ryan, J. C. Gigliotti, S. E. Alway, and J. C. Tou, "Resveratrol supplementation influences bone properties in the tibia of hindlimb-suspended mature Fisher 344 x Brown Norway male rats," Applied Physiology, Nutrition, and Metabolism, vol. 37, no. 6, pp. 1179-1188, 2012.

[50] O. Kutuk, M. Adli, G. Poli, and H. Basaga, "Resveratrol protects against 4-HNE induced oxidative stress and apoptosis in Swiss 3T3 fibroblasts," BioFactors, vol. 20, no. 1, pp. 1-10, 2004.

[51] Y. Zheng, Y. Liu, J. Ge et al., "Resveratrol protects human lens epithelial cells against $\mathrm{H}_{2} \mathrm{O}_{2}$ induced oxidative stress by increasing catalase, SOD-1, and HO-1 expression," Molecular Vision, vol. 16, pp. 1467-1474, 2010.

[52] D. H. Lee, B.-S. Lim, Y.-K. Lee, and H.-C. Yang, "Effects of hydrogen peroxide $\left(\mathrm{H}_{2} \mathrm{O}_{2}\right)$ on alkaline phosphatase activity and matrix mineralization of odontoblast and osteoblast cell lines," Cell Biology and Toxicology, vol. 22, no. 1, pp. 39-46, 2006.

[53] C. Krakstad and M. Chekenya, "Survival signalling and apoptosis resistance in glioblastomas: opportunities for targeted therapeutics," Molecular Cancer, vol. 9, article 135, 2010.

[54] K. Maiese, Z. Z. Chong, and F. Li, "Driving cellular plasticity and survival through the signal transduction pathways of metabotropic glutamate receptors," Current Neurovascular Research, vol. 2, no. 5, pp. 425-446, 2005.

[55] C. S. Yan, Z. C. Zhao, H. Jinling, and K. Maiese, "FoxO3a governs early microglial proliferation and employs mitochondrial depolarization with caspase 3, 8, and 9 cleavage during oxidant induced apoptosis," Current Neurovascular Research, vol. 6, no. 4, pp. 223-238, 2009.

[56] S. P. Tenbaum, P. Ordonez-Moran, I. Puig et al., “ $\beta$-catenin confers resistance to $\mathrm{PI} 3 \mathrm{~K}$ and $\mathrm{AKT}$ inhibitors and subverts FOXO3a to promote metastasis in colon cancer," Nature Medicine, vol. 18, no. 6, pp. 892-901, 2012.

[57] D. Chen, M. Zhao, and G. R. Mundy, "Bone morphogenetic proteins," Growth Factors, vol. 22, no. 4, pp. 233-241, 2004.

[58] T. Katagiri, A. Yamaguchi, M. Komaki et al., "Bone morphogenetic protein-2 converts the differentiation pathway of $\mathrm{C} 2 \mathrm{C} 12$ myoblasts into the osteoblast lineage," Journal of Cell Biology, vol. 127, no. 6 I, pp. 1755-1766, 1994.

[59] G. Rawadi, B. Vayssière, F. Dunn, R. Baron, and S. RomanRoman, "BMP-2 controls alkaline phosphatase expression and osteoblast mineralization by a Wnt autocrine loop," Journal of Bone and Mineral Research, vol. 18, no. 10, pp. 1842-1853, 2003.

[60] S. Y. Shin, C. G. Kim, E.-H. Jho et al., "Hydrogen peroxide negatively modulates Wnt signaling through downregulation of $\beta$-catenin," Cancer Letters, vol. 212, no. 2, pp. 225-231, 2004.

[61] Y. Funato, T. Michiue, M. Asashima, and H. Miki, "The thioredoxin-related redox-regulating protein nucleoredoxin inhibits Wnt-beta-catenin signalling through dishevelled," Nature cell biology, vol. 8, no. 5, pp. 501-508, 2006. 
[62] T. A. Bailey, N. Kanuga, I. A. Romero, J. Greenwood, P. J. Luthert, and M. E. Cheetham, "Oxidative stress affects the junctional integrity of retinal pigment epithelial cells," Investigative Ophthalmology and Visual Science, vol. 45, no. 2, pp. 675-684, 2004.

[63] Y. Chen, Y. Hu, T. Zhou et al., "Activation of the wnt pathway plays a pathogenic role in diabetic retinopathy in humans and animal models," American Journal of Pathology, vol. 175, no. 6, pp. 2676-2685, 2009.

[64] T. Zhou, K. K. Zhou, K. Lee et al., "The role of lipid peroxidation products and oxidative stress in activation of the canonical wingless-type MMTV integration site (WNT) pathway in a rat model of diabetic retinopathy," Diabetologia, vol. 54, no. 2, pp. 459-468, 2011. 


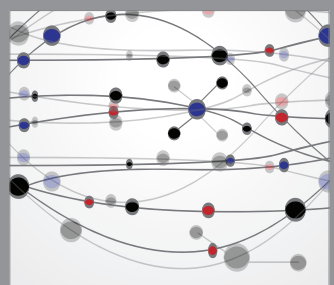

The Scientific World Journal
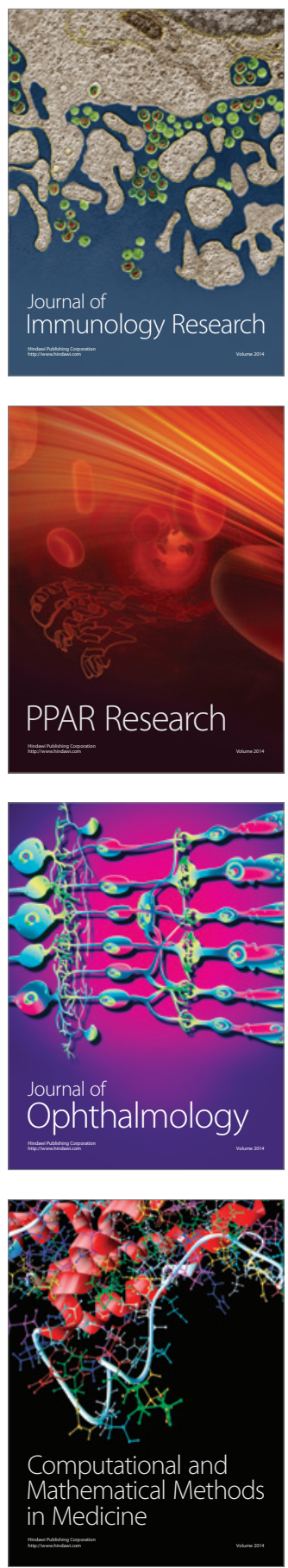

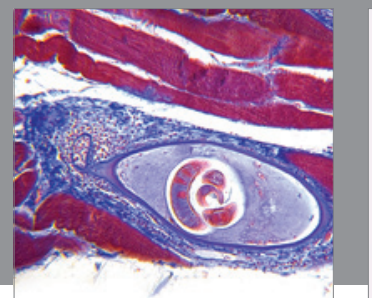

Gastroenterology

Research and Practice
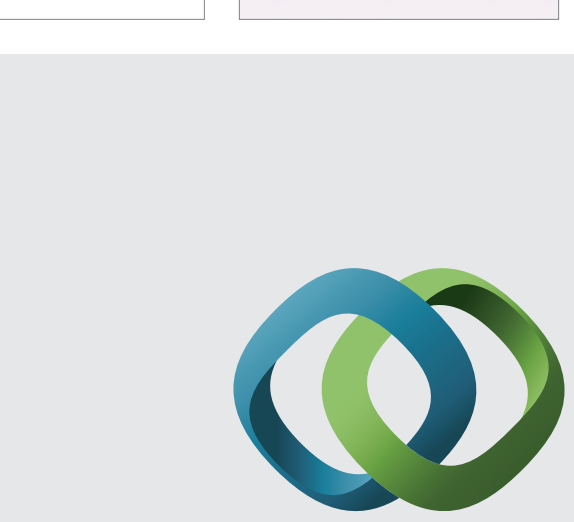

\section{Hindawi}

Submit your manuscripts at

http://www.hindawi.com
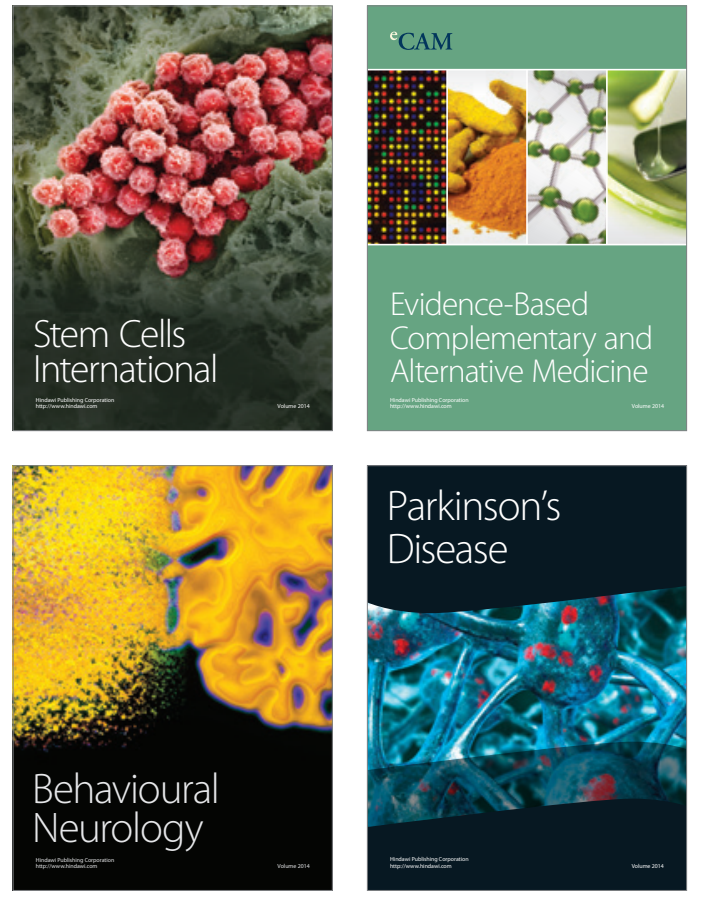
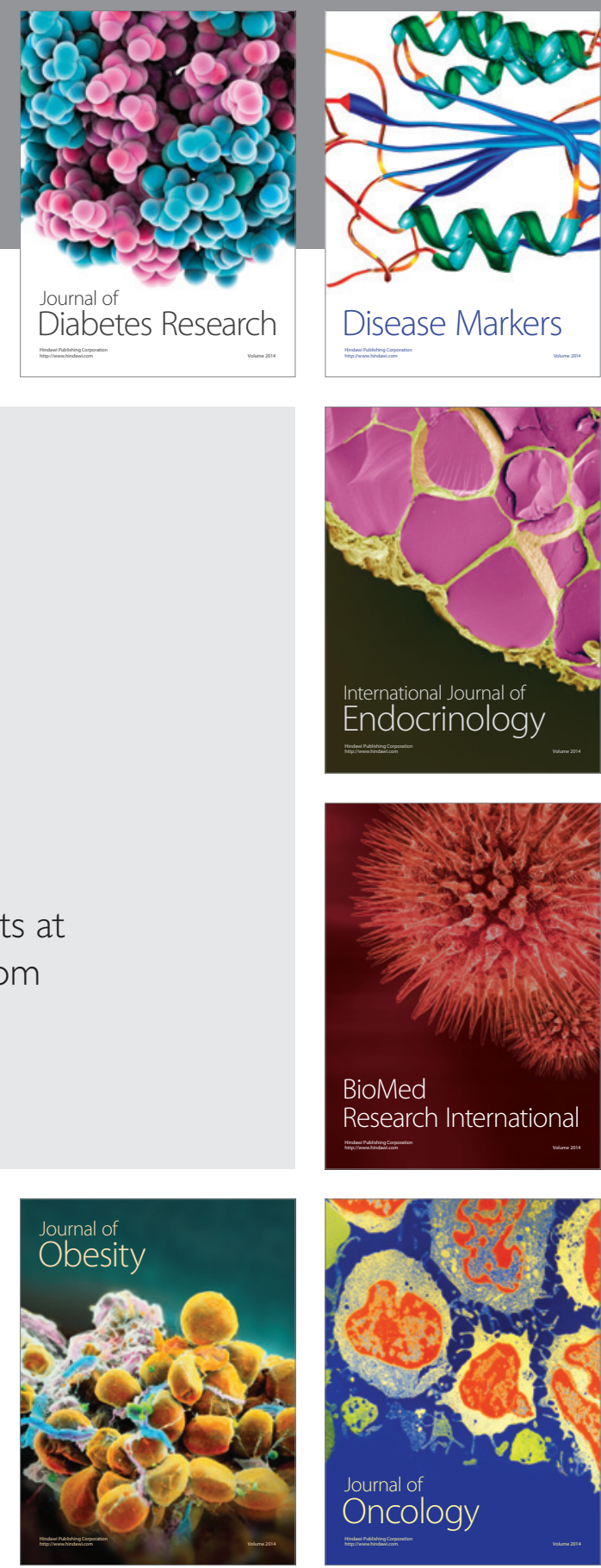

Disease Markers
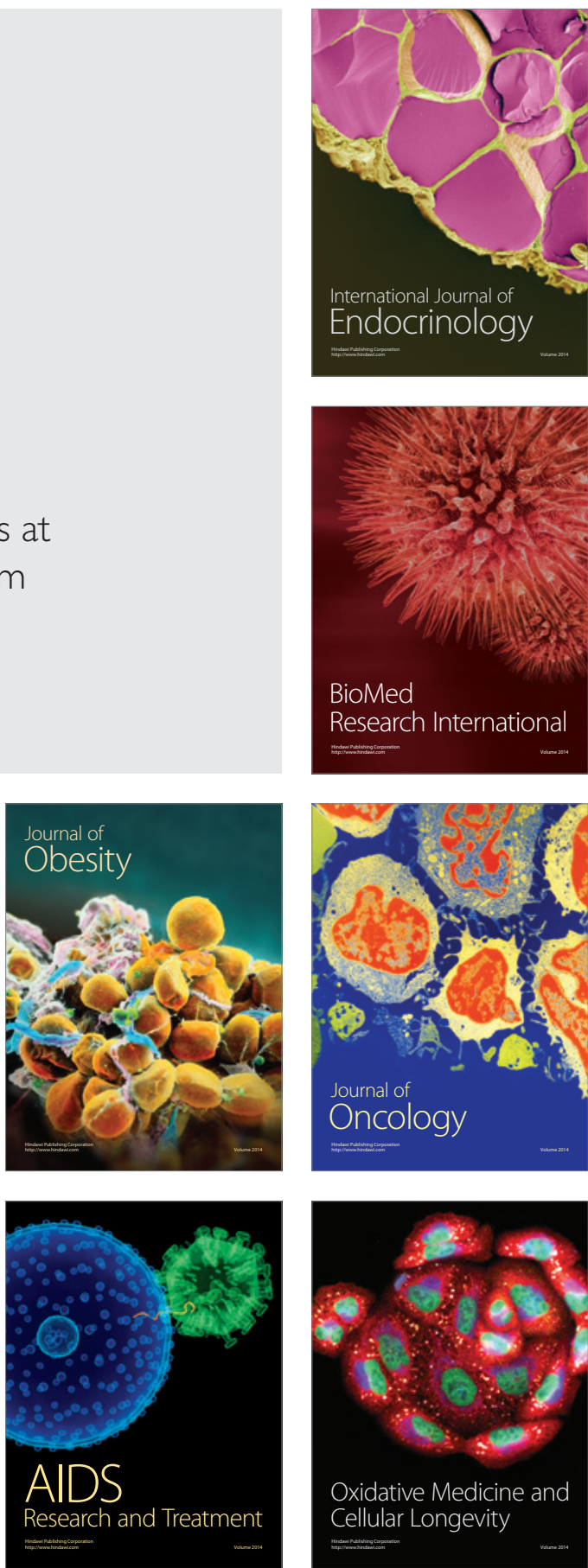